\title{
REVIEW OF
}

BACILLUS THURINGIENSIS

VAR. KURSTAKI (BTK)

FOR USE IN

FOREST PEST MANAGEMENT

PROGRAMS IN ONTARIO -

WITH SPECIAL EMPHASIS

ON THE

AQUATIC ENVIRONMENT

APRIL 1990 



\section{REVIEW OF BACILLUS THURINGIENSIS VAR. KURSTAKI (BTK) \\ FOR USE IN FOREST PEST MANAGEMENT \\ PROGRAMS IN ONTARIO - WITH SPECIAL EMPHASIS \\ ON THE AQUATIC ENVIRONMENT}

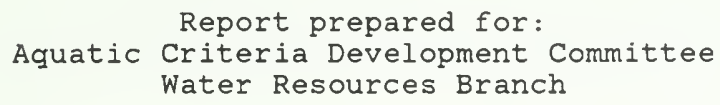

Report prepared by:

Dr. G. A. Surgeoner

M. J. Earkas

Department of Environmental Biology

University of Guelph

Guelph, Ontario

N1G 2W1

APRIL 1990

Copyright: Queen's Printer for Ontario, 1990

This publication may be reproduced for non-commercial purposes with appropriate attribution. 


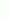




\section{PREAMBLE}

In response to the Ministry of Natural Resources' preparation of Class Environmental Assessment for timber management on crown lands, the Ontario Ministry of the Environment (MOE) commissioned the Environmental Review of Bacillus thuringiensis var. kurstaki (Btk) for Use in Forest Pest Management Programs of ontario with Special Empasis on The Aquatic Environment.

This review focuses on the aquatic ecosystem effects of Btk as they relate to the control of insect infestations on crown lands. The review also considers the effects of Btk on non-target terrestrial biota (wildlife and humans) as they relate to the exposure of these lifeforms through the contact and ingestion of contaminated water and/or biota.

The intent was to develop a Provincial Water Quality objective (PWQO) from the information provided in the review document. However, the difficulty in enumerating Btk in water has prohibited the development of a numerical PWQO. Instead, a narrative

ENVIRONMENTAL IMPACT STATEMENT has been prepared and is provided on the following pages. 


\section{ENVIRONMENTAL IMPACT STATEMENT}

The accumulated information suggests that no significant impacts on aquatic or on other beneficial uses of Provincial surface waters would result from the properly planned, controlled and supervised use of Bacillus thuringiensis var. kurstaki (Btk) for the control of forest pests.

\section{RATIONALE}

\section{INTRODUCTION}

Bacillus thuringiensis (Bt) is a gram positive, mobile, aerobic bacteria closely related to the ubiquitous soil bacteria Bacillus cereus. There are at least 20 recognized sub-species (serotypes, varieties) and 800 strain isolates of Bt (de Barjac 1981, pp. 4041). Bacillus thuringiensis var. kurstaki (Btk) is a strain selected for high potency against Lepidoptera larvae.

In Canada, 17 formulations of $B t k$ have been registered for the control of Lepidopterous pests. Formulations exist in Canada for control of Lepidopterous pests on a variety of commercial vegetables as well as for home and garden use. In ontario, the Ministry of Natural Resources uses Btk (when required) for the control of the spruce budworm, (Choristoneura fumiferana), the jack pine budworm, (Choristoneura pinus), and the gypsy moth, (Lymantria dispar). Most forestry applications in ontario are applied under contract to the Ministry of Natural Resources.

Btk is grown in a media which contains carbon, nitrogen and trace minerals. In response to reduced available nutrients the bacteria sporulates forming at one end of the cell a dormant endospore and at the other end the protein crystal, which contains the toxin, delta-endotoxin, causing Lepidoptera mortality. Once sporulation has been completed the media is treated to destroy vegetative cells. Endospores and crystals in approximately equal numbers are separated from the fermentation broth (growth media) and spray dried to form a fine technical powder. Each fermentation batch of Btk undergoes quality assurance tests for microbiological contamination and a mouse test to ensure no effects against mammalian organisms. It is the concentrations of certain proteins making up the crystal and endospore coat that determine the potency of Btk, not the number of protein crystals and endospores.The rate of application for a typical treatment would be approximately 30 BIU per hectare. 


\section{ENVIRONMENTAL FATE}

After application, Btk looses $50 \%$ of its insecticidal activity in 1-3 days. However, some viable endospores have been recovered from foliage one year after ground application. Persistence of Btk on foliage is dependent on many environmental factors including length of exposure to sunlight (ultra-violet radiation), leaf temperature and vapour pressure deficit.

Bacillus thuringiensis (Bt) can survive as endospores in most types of soils, although Bt will not grow at pH below 4.8 . Bt may persist in soils for up to several months. The fate of Bt in soils is dependent upon microbial competition. Studies have shown that the relative number of $\mathrm{Bt}$ compared to other soil bacilli was reduced from 20-40\% to about $10 \%$ over a 12 month period indicating that $B t$ is not well adapted to the soil environment. Bt has also been shown to be immobile in soils.

Btk may directly enter the aquatic environment during spray operations since no spray buffer zones between application areas and surface waters are required. Btk may be transported to surface water bodies in the wash-off from treated trees and the subsequent surface run-off. Btk may persist as viable spores in lake waters for a considerable length of time ( $>70$ days). However, in streams and rivers Btk is far less persistent.

\section{EFFECTS ON TERRESTRIAL LIFE}

of the beneficial arthropods which were exposed to Dipel ${ }^{R}$ (Btk), only one species, syrphus showed slight effects. At the minimum recommended field dose, Btk (as Thuricide HPC $^{R}$ ) had little or no effect on parasites and predators of the spruce budworm. Post treatment longevity of cardiochiles nigriceps (a tobacco budworm parasitoid) was decreased after ingestion of Btk (Dipel ${ }^{R}$ and Biotrol $\mathrm{XK})$ dissolved in sugar water. The researchers contend that $C$. nigriceps would not feed on Btk in the field, and only fed on it in the laboratory since the sugar acted as an attractant. Bees and wasps exposed to Btk showed no effects. Btk also did not reduce emergence of parasites or percentage parasitism of the European corn borer.

To determine the effects of Btk on natural enemies of the western spruce budworm, parasite studies were conducted by Niva et al., (1987) during field tests of two Btk formulations (San $\overline{41}$ and Thuricide $32 \mathrm{LV})$. The results indicated that infected parasites 
matured sufficiently to exit from their hosts, but were unable to complete their development. However, premature parasite mortality may have been due to lack of nutrition caused by the early deaths of their hosts, rather than microbial infection.

Significant mortality $(<13.4 \%$ ) was noted in adult chrysopa carnea and Hippodamia convergens 3 to 7 days after exposure to Btk, at dosages approximately 4 to 8 times greater than that which would reach insects under normal field applications.

No significant reductions in bird populations (74 species representing 21 families) were apparent in areas treated with Bt: (with and without chitinase), in canadian spruce-fir forest treatment plots, located in spruce Woods, Manitoba and Algonquin Park, ontario. Laboratory tests with pheasants, partridges, cornish hens, and quail, exposed orally to Bt, yielded no effects. Sparrows and juncos administered $0.25 \mathrm{ml}$ of $3 \times 10^{\circ}$ spores $/ \mathrm{ml}$ daily by syringe for 2 weeks exhibited no mortality, weight loss or change in the appearance.

The possibility of indirect effects to birds, specifically spruce grouse, due to reduced food availability has been raised. However, it was shown that the year after spraying, the number of mating pairs observed were not significantly different than the previous year.

Tests exposing rats, mice, guinea pigs, young swine and hogs orally to Bt by placing it directly into the stomachs or administering it in the feed resulted in no symptoms of toxicity.

Sensitizing doses of Thuricide ${ }^{R}$ were given to guinea pigs by intracutaneous injection, the abrasion patch technique and topical application on intact skin. Local irritation was found in injected and abraded animals. No effects were observed from challenging doses given two weeks after the last sensitizing treatment. Topical applications also had no effect.

In addition to the oral, intraperitoneal, respiratory, dermal and hypersensitivity tests, Bacillus Thuringiensis has passed the eye exposure (in rabbits) and mutagenicity (in vitro) safety tests.

Field studies on plots treated with Bt in Algonquin Park, ontario and Spruce Woods, Manitoba indicated that small mammals continued breeding through treatment periods and trapping data indicated that the application of Bt treatments (with and without chitinase) did not harm the small mammal complex inhabiting treatment areas.

\section{EFFECTS ON AQUATIC LIFE}

In the review of Btk toxicity to fish, few published scientific papers pertaining to modern Bt formulations were found. The older 
formulations presumably contained beta-exotoxins which are more toxic to vertebrates. Therefore, studies conducted with the older formulations would indicate greater toxicity to fish than would be found with Bt formulations currently on the market today.

The toxic concentrations of Bt to fish in laboratory tests were typically 1,000 fold higher than those derived from field applications. Little or no effects were observed when rainbow trout, yellow perch, mosquito fish or black bullhead fingerlings were exposed for 4 days to concentrations of 4.5 to $6.5 \times 10^{4}$ spores $/ \mathrm{ml}$. Effects probably due to the petroleum carrier occurred at a dose of $>6 \times 10^{7}$ spores/ml.

A field evaluation of Thuricide $16 \mathrm{~B}$ applied in Algonquin Park, ontario at an estimated rate of 17.6 BIUs per hectare, showed no adverse effects to fish populations (brook trout, white suckers, smallmouth bass) and bottom fauna populations, in rivers for up to four weeks post treatment. The lack of any documented fish kills resulting from any of the forestry or agricultural spray programs involving Btk across Canada and the United states is additional, and probably the most valid evidence, of the safety of Btk to fish.

In a laboratory study a variety of aquatic invertebrates were exposed to Btk (Thuricide $32 \mathrm{LV}$ ) at 2, 20 and 200 times the worstcase transitory concentration expected in water after aerial spraying. Only the black fly (simulium vittatum) was clearly affected at the highest exposure $(430 \mathrm{IU} / \mathrm{ml})$ with $75 \%$ mortality to the test population. Some impact was suggested for prosimulium Fuscum/mixtum (Simuliidae) and the midge Tanytarus (Chironomidae) in the same study. Monitoring of water bodies during spray programs have shown that Btk had no measurable effects on a large variety of aquatic invertebrates. The most susceptible aquatic invertebrates are black fly and chironomid larvae. However, no effects have been reported at concentrations occurring from aerial applications.

\section{HUMAN HEALTH EFFECTS}

Despite wide spread use of Bt throughout the world only one incidence of a corneal ulcer in a farm worker, apparently caused when a Btk formulation was splashed into the eye, has been reported. This is the only documented infection in humans and other vertebrates. Antibiotic treatment resulted in complete recovery of the farm worker. No effects were observed in a study, in which eighteen volunteers ingested $1 \mathrm{~g}$ of Thuricide /day for 5 days at a concentration of $3 \times 10^{\circ}$ viable spores/g; and 5 of the test subjects also inhaled an additional loomg of the powder daily over the 5 day period and showed no effects. All people tested remained healthy and all the extensive laboratory tests were negative. 



\section{Table of contents}

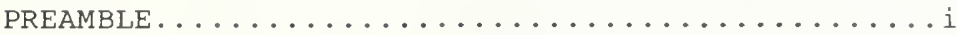
ENVIRONMENTAL IMPACT STATEMENT.............. ii

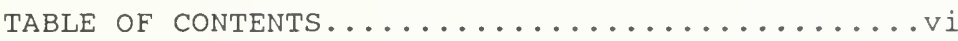

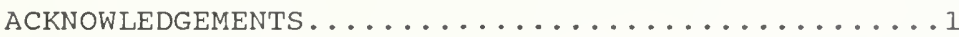

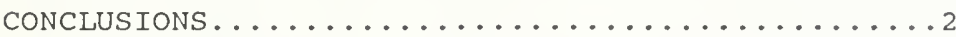

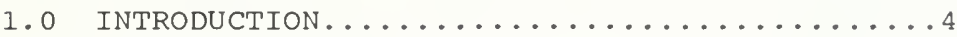

2. 0 GENERAL DESCRIPTION

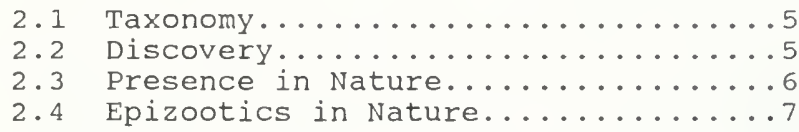

3. 0 PRODUCTION PROCESS

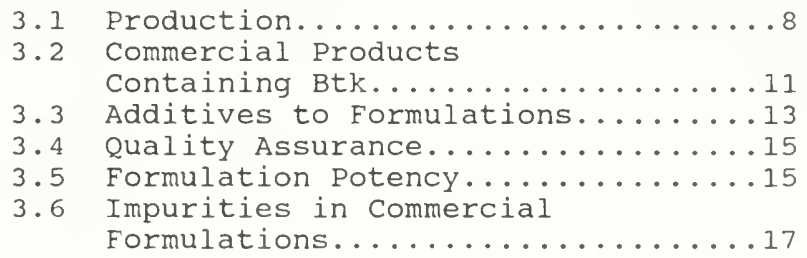

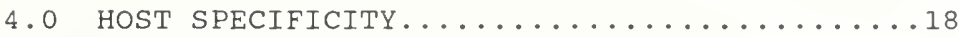

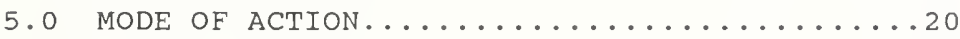

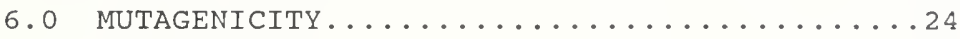

7.0 SPRAYING/APPLICATION PRACTICES..........25

8.0 METHODS FOR ENUMERATING BTK FROM ENVIRONMENTAL SAMPLES...................

9.0 ENVIRONMENTAL FATE

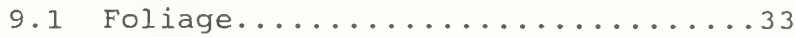

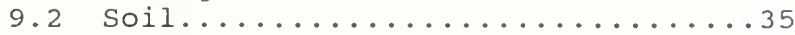

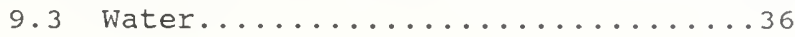


10.0 AQUATIC TOXICITY

10.1 Expected Exposure Levels.........38

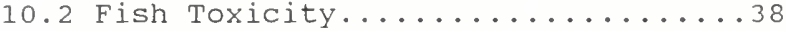

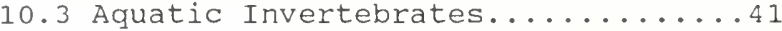

11.0 HEALTH EFFECTS (TO HUMANS)............... 45

12.0 EFFECTS ON NON-TARGET TERRESTRIAL ANIMALS

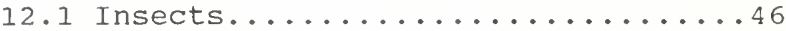

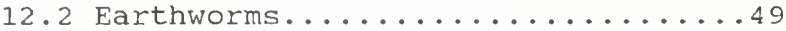

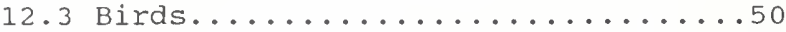

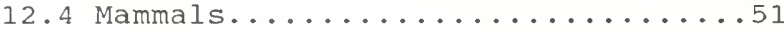

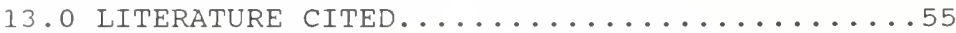

14.0 APPENDICES

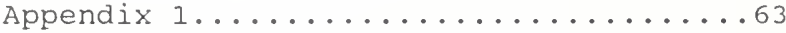

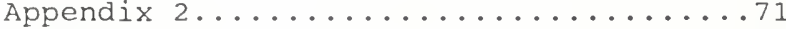

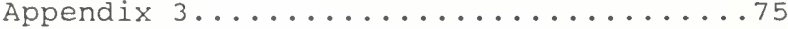

Appendix $4 \ldots \ldots \ldots \ldots \ldots \ldots 6 . \ldots \ldots$ 


\section{ACKNOWLEDGEMENTS}

The authors wish to thank the numerous personnel from the Federal Pesticides Directorate, Forest Pest Management Institute, Ministry of Natural Resources, and industry, who assisted in answering questions. Particular thanks to Joe Churcher (Ministry of Natural Resources), Peter Kingsbury (Forest Pest Management Institute) and Barry Tyler (Abbott Laboratories).

We would also like to thank the staff of the Ontario Ministry of the Environment: C. Cherwinsky, C. de Barros, E. Leggatt, D. Poirier, J. Ralston, and D. Rokosh who assisted in the review of the draft manuscript and provided many useful comments. 


\section{CONCLUSIONS}

1) The scientific literature indicates that Bacillus thuringiensis var. kurstaki directly affects only Lepidoptera larvae.

2) In ontario, the use of this bacteria has been extensive, with over 1.2 million hectares of forest treated in the past 7 years for control of the spruce budworm (Choristoneura fumiferana), the jack pine budworm (Choristoneura pinus), and the gypsy moth (Lymantria dispar).

3) The use of Bacillus thuringiensis var. kurstaki, for forestry purposes in ontario, is restricted to licensed applicator personnel.

4) Based on the scientific literature, the use of Bacillus thuringiensis var. kurstaki does not represent a detectable impact to the quality of surface waters in the Province of ontario.

5) The use of Bacillus thuringiensis var. kurstaki may reduce nontarget Lepidoptera, some of which may be rare. Studies should be initiated to determine the effects of aerial applications of Btk to 
Lepidoptera larvae, particularly those feeding on understory vegetation.

6) The reduction of Lepidoptera larvae caused by Bacillus thuringiensis var. kurstaki may result in reduced food availability to certain birds (e.g. spruce grouse) thus affecting nesting success. Studies should be continued to determine if indirect effects to birds are significant mortality factors. 


\subsection{INTRODUCTION}

The Ontario Ministry of Natural Resources has recently completed a draft, class Environmental Assessment, for timber management on crown lands. Under this class Environmental Assessment, the Ministry of Natural Resources proposes (when required) to use Bacillus thuringiensis var. kurstaki (Btk) for control of the spruce budworm, choristoneura fumiferana, the jack pine budworm, Choristoneura pinus, and the gypsy moth, Lymantria dispar.

The potential for this "biological" insecticide to enter surface water during and after application to timber lots is of potential concern to the ontario Ministry of the Environment. The Ontario Ministry of the Environment has been mandated to develop, and where appropriate, revise the Provincial water Quality objectives and Policies to protect the provinces's water resources. These water quality objectives and policies are designed to assure that "...surface waters in the province are of a quality which is satisfactory for aquatic life and recreation".

In order to formulate a sound environmental policy for Btk, the available scientific data must be procured and analyzed. The purpose of this document is to provide the current information known about this compound with particular emphasis on protecting surface waters. 


\section{2 . 0 GENERAL DESCRIPTION}

\subsection{Taxonomy}

Bacillus thuringiensis (Bt) is a gram positive, mobile, aerobic bacteria closely related to the ubiquitous soil bacteria Bacillus cereus. Vegetative cells of Bt are approximately 1 um wide by 5 um long. The species is separated from B. cereus by its greater pathogenicity to insects and its ability to produce a bipyrmidal inclusion body (protein crystal) during sporulation (Heimpel 1967, pp. 288-291).

The term Bacillus thuringiensis in many ways is misleading since there are at least 20 recognized subspecies (serotypes, varieties) and 800 strain isolates (de Barjac 1981, pp. 40-41). Any documentation associated with Bt must include both the serotype and strain being used and a potency comparison to an accepted international reference standard. Bacillus thuringiensis var. kurstaki is a strain selected for high potency against Lepidoptera larvae. It does not contain "beta-exotoxins" which exhibit some mammalian toxicity and potential mutagenicity. This toxin is found in certain varieties of Bt, i.e. Bacillus thuringiensis

thuringiensis. The various toxins associated with Bacillus thuringiensis are described in section 5.0 Mode of Action.

\subsection{Discovery}

Bacillus thuringiensis was first isolated from diseased silkworm larvae in Japan in 1901. It was subsequently given 
taxonomic validity by Berliner who isolated bacteria from diseased Mediterranean flour moths from the Province of Thuringen in East Germany. It was thus given the scientifically valid name of Bacillus thuringiensis Berliner. This original strain is now designated Bacillus thuringiensis var. thuringiensis. The isolate Bacillus thuringiensis var. kurstaki was first isolated in France by kurstak in 1962 but the strain used for commercial North American production was isolated by Dulmage in 1970 from a laboratory colony of diseased pink bollworm larvae in the U.S. The particular isolate of Btk used in commercial formulations is known as Btk-HDl strain. It is approximately $15 \mathrm{X}$ more potent to Lepidoptera larvae as previous Bt isolates. The HD refers to Howard Dulmage who made the original isolate.

\subsection{Presence in Nature}

Bacillus thuringiensis can grow in moist soils, deriving nutrients from decaying plants and can grow in tissues of infected insects (Ghassemi et al. 1981). In natural soils, Btk only exist in the spore state (Akiba 1986). Strains of Bt have been discovered in many regions of the world, ie. Japan (silkworms); Germany (flour moths); France (original Btk); Israel (Bti); Kenya (Bt kenyae); the United States (Btk HD-1) and Canada (Bt canadensis). This indicates that the bacteria has a natural cosmopolitan distribution wherever insects occur. Krieg and Langenbruch (1981, p. 841) list the origins for 24 varieties of Btk.

In Japan, Bacillus thuringiensis is readily isolated from the litter beneath sericultural farms (11.4\% of bacterial isolates). 
It is, however, relatively rare in the forest soils of Japan with a frequency of $2.7 \%$ of bacterial isolates (Ohba and Aizawa 1986). In the United states, Delucca et al. (1981) in a survey of soils never previously treated with Bt, found that it occurred with a frequency of $0.75 \%$ in the approximately 32,000 bacteria isolates obtained, indicating that it is relatively rare in "natural soils". It was, however, found in $17 \%$ of soils tested, in a wide variety of soil types, ie. grass, rocky wooded area, and in soil pH's ranging from 4.9 to 8.0. Various strains of Bt have been commonly found in grain elevators and grain dusts. DeLucca et al. (1982) reported Bt isolates from $55 \%$ of settled dust samples and $16.9 \%$ of respirable dust samples in four large grain elevators near New orleans. There was no evidence of insects in any of the elevators at the time of sampling.

\subsection{Epizootics in Nature}

The original isolation of Bt was made during investigation of "sotto disease" affecting commercial silkworm production in Japan (Delucca et al. 1981). It was next isolated in Germany by Berliner in association with an infestation of Mediterranean flour moths in stored grains. These natural epizootics and others reported, ie. sericulture in Japan, stored grains in Kenya and insect cultures, all indicate that natural epizootics of Bt occur only when insects are maintained in high densities within a confined area (DeLucca et al. 1981). Dulmage and Aizawa (1982) cite a study by Van der Laan and Wassink (1969) where they attempted to initiate infections from Bt-killed larvae into susceptible hosts. It was found that natural 
infections from sick or dead larvae to susceptible hosts did not occur. Epizootics caused by Bt rarely occur in nature although background levels exist in soil samples and grain dusts (Dulmage and Aizawa 1982). Like chemical insecticides, Btk should not be expected to have any carry-over effects the following year. Unexplained benefits to plots treated with Btk for spruce budworm have been observed in the year following treatment (Dimond and spies 1981).

\subsection{PRODUCTION PROCESS}

\subsection{Production}

The Bacillus thuringiensis var. kurstaki used for insecticide formulations are produced in large fermentation vats (up to 130,000 litres) similar to those used for the commercial production of antibiotics. For North America, there are three primary suppliers of Btk: 1) Abbott Laboratories with production facilities in Chicago, Illinois, 2) Duphar with primary production in Belgium, and 3) Sandoz with primary production near san Francisco, California. The active ingredient Btk is not produced in Canada but some formulating does occur in association with chemagro in ontario.

The media for bacterial growth and actual media environment (ie. pH, temperature, aeration level) are proprietary information unavailable for this review. Each company would have slightly different methodologies of production. The basic production concept is similar for all companies (Fig.1). 


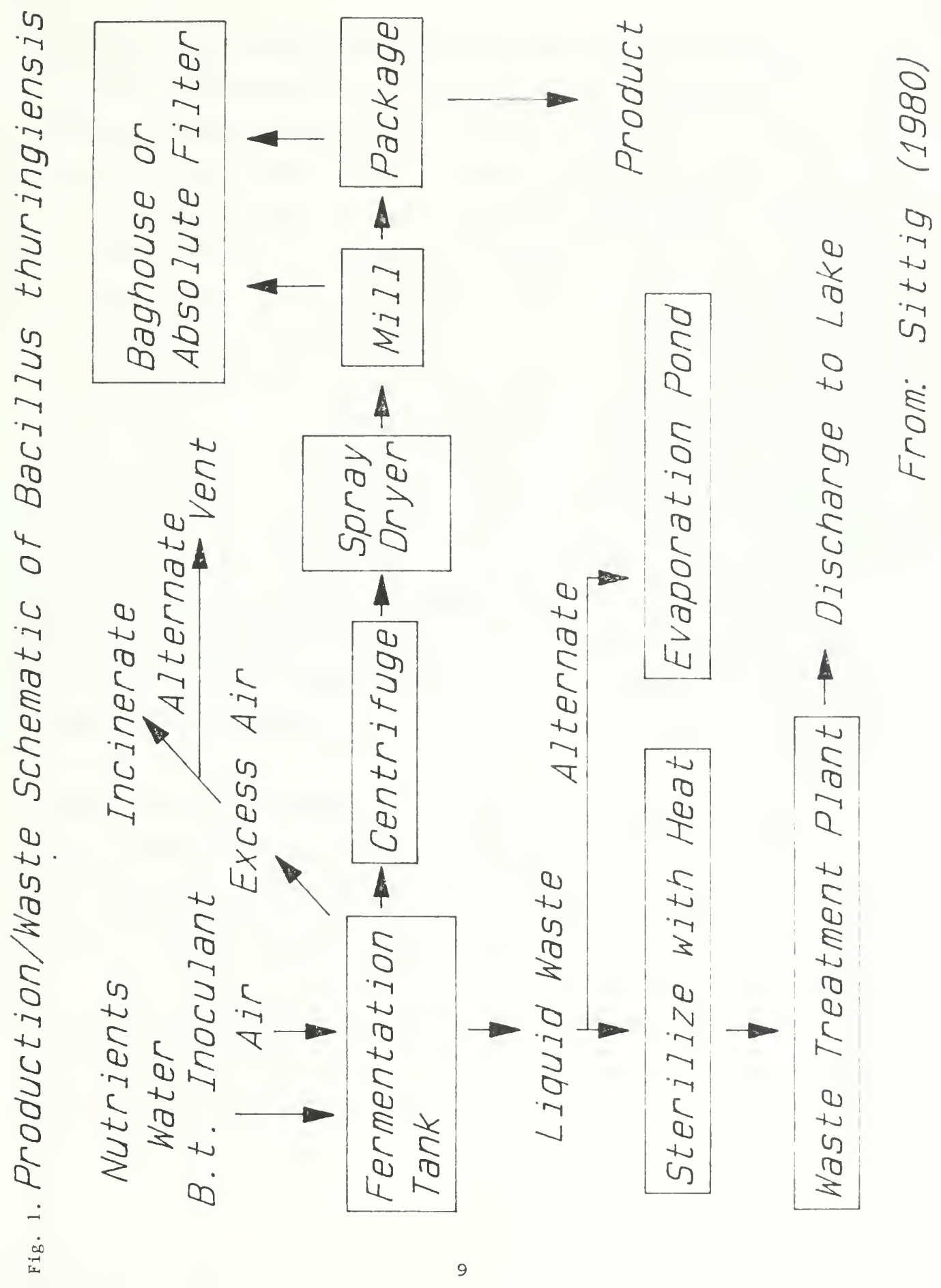


The media for bacterial growth must contain carbon, nitrogen and trace minerals. In discussions with companies these are obtained from normal commodity raw products. Typical nitrogen sources may include fish meals, cotton seed flour, soybeans, autolyzed yeasts and casein. Carbohydrate sources include hydrolyzed corn products, starch and dextrose. Trace minerals would be available in these carbon and nitrogen sources. The fermentation medium ingredients for the U.S. reference standard include: generic tryptone $(10 \mathrm{~g} / \mathrm{L})$, powdered corn $(5 \mathrm{~g} / \mathrm{L})$, generic yeast extract (2 g/L, $\mathrm{K}_{2} \mathrm{H} \mathrm{PO}_{4}$ and $\mathrm{KH}_{2} \mathrm{PO}_{4}$ each at $1 \mathrm{~g} / \mathrm{L}$ ) (Beegle et al. 1986).

Once the media has been formulated it is steam sterilized to prevent microbial contamination. Isolates of Btk HD-1 strain are inoculated into the media to initiate cell growth. Inoculum amounts range from 2 to 5\% of the fermenter volume. The media is then slowly agitated and provided with an abundant supply of sterilized air. The $\mathrm{pH}$ of the fermenter tanks is typically between 7.2 and 7.6. The temperature of the tanks is maintained at approximately $30^{\circ} \mathrm{C}$.

After approximately five days of vigorous vegetative growth the bacteria in response to reduced available nutrients begin to sporulate forming at one end of the cell a dormant endospore and at the other end the protein crystal, which contains the toxin (deltaendotoxin), causing Lepidoptera mortality.

Once sporulation has been completed the media is treated to destroy vegetative cells. The spore-crystal complex can be exposed to temperatures of $100^{\circ} \mathrm{C}$ for short periods of time without 
degradation. Endospores and crystals in approximately equal numbers are concentrated from the fermentation broth by either centrifugation or filtration. The resultant spores and crystals are spray dried to form a fine technical powder. This powder is then bioassayed against the cabbage looper Trichoplusia ni (Hubner) using accepted standard bioassay techniques. Individual batches from fermentaters will vary somewhat in their potency. Potency is not directly related to the number of endospores or the number of protein crystals. It is the concentrations of certain proteins making up the crystal and endospore coat that determine the potency of the Btk. The technical powders are allowed by international agreement $\pm 20 \%$ variance from the stated potency. Each bioassay will give slightly different results with the same technical powder.

\subsection{Commercial products containing Btk}

In Canada, 17 formulations of $B t k$ have been registered for control of Lepidopterous pests in forestry (Table 1). In addition, other formulations exist in Canada for control of Lepidopterous pests on a variety of commercial vegetables. Formulations also exist which have a domestic registration for availability to home gardeners. There is no post-harvest interval or re-entry time associated with the use of Btk, i.e. control of cabbage worm can be made up to the day of harvest (OMAF 1988).

In the United States, the major use for Btk is against agricultural pests of cole crops, alfalfa and cotton, and 
Table 1. Commercial products of Btk With Potential Forestry Uses

$\begin{array}{llll}\text { Name } & \text { Manufacturer } & \text { Under PCPA' } & \\ \text { Dipel F } & \text { Abbott } & 13299 & \\ \text { Dipel SC } & \text { Abbott } & 14082 & 16.0 \mathrm{BIU} / \mathrm{mg} \\ \text { Dipel 88 } & \text { Abbott } & 16873 & 9.9 \mathrm{BIU} / \mathrm{g} \\ \text { Dipel 132 } & \text { Abbott } & 17954 & 8.5 \mathrm{BIU} / \mathrm{L} \\ \text { Dipel 176 } & \text { Abbott } & 20599 & 12.7 \mathrm{BIU} / \mathrm{L} \\ \text { Novabac - 3 } & \text { Duphar B.V. } & 17133 & 12.7 \mathrm{BIU} / \mathrm{L} \\ \text { Futura XLV } & \text { Duphar B.V. } & 20861 & 8.6 \mathrm{BIU} / \mathrm{L} \\ \text { Futura } & \text { Duphar B.V. } & 17778 & 12.7 \mathrm{BIU} / \mathrm{L} \\ \text { Bactospeine F Duphar B.V. } & 17782 & 14.4 \mathrm{BIU} / \mathrm{L} \\ \text { Novabac - 3 Cyanamid } & 15084 & 9.7 \mathrm{BIU} / \mathrm{L} \\ \text { Pfizer } & \text { Pfizer } & 18334 & 8.6 \mathrm{BIU} / \mathrm{L} \\ \text { Evirobac ES } & & 9.7 \mathrm{BIU} / \mathrm{L} \\ \text { Thuricide HPC Sandoz } & 11302 & \\ \text { Thuricide48LV Sandoz } & 17980 & 12.7 \mathrm{BIU} / \mathrm{L}\end{array}$

1) PCPA: Pest control Act

2) Guarantee is evaluated in terms of potency which is measured in Billion International Units (BIU) per unit volume of weight, reflecting the biological activity of the formulation against larvae of the cabbage looper, Trichoplusia ni in a standardized bio-assay. 
approximately $3 \%$ is used against forestry pests (Dubois and Lewis 1981). Over one million pounds of formulated Btk are applied annually in the United States (DeLucca et al. 1981).

\subsection{Aditives to Formulations}

Initial products with Btk were crude powders of spores, crystals, growth media and inert ingredients. Formulations had suspendability problems, clogged spray systems and provided inconsistent control. Today, Btk formulations are primarily spore and crystal concentrates, prepared for use primarily as water suspensions or oil emulsions. Additives such as thickening agents have been incorporated into formulations to provide uniform suspensions, wetting agents to obtain better leaf coverage, antievaporants, stickers to increase retention of spray deposits and sun screens to reduce the degradation of crystals by UV radiation. A product such as "Thuricide 16B" contains $0.34 \% \mathrm{Btk}, 48.15 \%$ culture media, $1.5 \%$ xylene, $0.01 \%$ Chevron sticker and $49.99 \%$ water (Menon and Mestral 1985). (It should be noted that "Thuricide $16 \mathrm{~B}$ is no longer in use in Canada and no forestry Btk forestry products presently contain xylene). Concern has been expressed about potential toxicity of these inert ingredients (Orton 1987). Although individual components of carriers are not listed, it has been shown that carrier fluid of non-aqueous oil formulations caused less than $2.1 \%$ mortality to non-target insects in laboratory trials (Haverty 1982). The Dipel oil vehicle also did not affect target spruce budworm larvae (Morris 1983). Since target organisms and non-target insects 
are unaffected by "oil carriers", it is reasonable to assume that they will not affect larger organisms. Product labels indicate the potency guarantee of the Btk but do not include concentrations of other "inert" ingredients. These "inert" ingredients are critical to the success of new formulations and are proprietary rights of companies.

As shown by Fortin et al. (1986) (see aquatic toxicity section) and the concern of micro contaminants (Agriculture Canada letter, Appendix 1) the "inert ingredients" are perhaps the most toxic components of Btk formulations. Their toxicities will be minor when one considers the amounts applied in operational control programs, and published studies done on "vehicle carriers" in the literature (Haverty 1982, Morris 1983). Proprietary toxicology data does exist on many of these standard "inerts" and on the formulated product. Federal agencies such as the Environmental Protection Service, Health and Welfare, and Fisheries and Ocean have reviewed this documentation. With permission of companies this information could likely be obtained from the companies or Pesticides Directorate in ottawa.

Most formulations are now being applied in mixtures with water (often at a 50/50 ratio) but the increasing tendency to reduce application costs has been to spray the products "neat", ie. undiluted. In 1988, all aerial applications in ontario were made using undiluted product at the rate of $2.4 \mathrm{~L} / \mathrm{ha}$ (pers. comm. $\mathrm{C}$. Howard). These products were applied primarily as oil-based emulsions. 


\subsection{Quality Assurance}

Each fermentation batch of Btk undergoes two quality assurance tests, the first of which is mammalian (mouse). Five laboratory white mice weighing 17-23 gm are injected subcutaneously with one million spores of Btk from each batch lot. The mice are observed for seven days. If there is any evidence of infection, skin reaction or mortality the tests would be repeated. If reactions continue the batch would be destroyed. Primary product released for formulation must have no effect on mice injected subcutaneously with one million spores. The other quality assurance check involves examination for microbial contaminants and is discussed under "Impurities in commercial formulations."

\subsection{Formulation Potency}

Standardization of Btk products is accomplished by bioassays rather than analytical procedures since the active ingredient(s) is unknown (proteins) and may actually consist of several different proteins. Numbers of bacterial spores or parasporal crystals do not provide reliable standards of potency. The accepted potency standard is the International Unit (IU) which is derived from bioassays.

The reference standard (designated E-61) maintained by the Pasteur Institute was derived from Bacillus thuringiensis var. thuringiensis and was given an arbitrary potency of $1,000 \mathrm{IU} / \mathrm{mg}$ (Luthy et al. $1982)$. 
In 1970, Btk became the subspecies for production of commercial formulations of Bt in North America. This strain derived from pink bollworms was called the HD-l strain after its discoverer Howard Dulmage. The lack of beta-exotoxins and high potency to Lepidoptera larvae (15X higher than previous isolates) made this strain commercially feasible and desirable.

In 1972, a preparation of HD-1, named HD-1-S-1971 was adopted as the primary United states and canadian reference standard. It was assigned a potency of $18,000 \mathrm{IU} / \mathrm{mg}$ (Dulmage 1973). This standard was subsequently changed to HD-1-S-1980 due to depletion of the HD1-S-1971 stock and differential activity of this strain between the cabbage looper Trichoplusia $\underline{\mathrm{ni}}$ and tobacco budworm Heliothis virescens. This reference standard to which current Btk production is compared has a potency of $16,000 \mathrm{IU} / \mathrm{mg}$ (Beegle et al. 1986). The standard is stored at $-16^{\circ} \mathrm{C}$ at USDA, Brownsville in $25 \mathrm{~g}$ aliquots and is available free of charge upon request.

All batches of Btk from commercial fermenters are compared to this HD-1-S-1980 standard. Thus, if a particular batch in bioassays was found to be twice as toxic to Trichoplusia ni as the reference standard, it would be assigned a value of $32,000 \mathrm{IU} / \mathrm{mg}$.

Many products use this potency in the name of the product. Thus, Dipel 176 would have a potency of 17,600 IU/mg or Dipel 132 a potency of $13,200 \mathrm{IU} / \mathrm{mg}$. The primary powder is then diluted with vehicle carriers and a potency on the basis of Billion International Units per litre of product is provided, ie. 
Base powder

Futura Suspension

Dipel $\quad 132$

Thuricide $48 \mathrm{LV}$
$12,000 \mathrm{IU} / \mathrm{mg}$

$13,200 \mathrm{IU} / \mathrm{mg}$

$12,000 \mathrm{IU} / \mathrm{mg}$
Final product

$14.4 \mathrm{BIU} / \mathrm{L}$

$12.7 \mathrm{BIU} / \mathrm{L}$

$12.7 \mathrm{BIU} / \mathrm{L}$

It is the potency of the final product in litres, ie. number of Billion International Units (BIU) per litre which best reflects the toxicity of the specific product to lepidopterous larvae. The IU/mg is an explanation of the potency for the technical material, whereas, the BIU's per litre is a measure of toxicity for the product used in the spray programs.

\subsection{Impurities in commercial Formulations}

In 1987, concerns were expressed regarding the presence of microcontaminants, specifically fecal streptococcus ( $\underline{S}$. faecium) in formulations of Btk (Cabana and Pelletier 1986). The relevance of these contaminants in regard to human health were determined by an advisory committee of the pesticides Directorate, ottawa to be minor. Streptococcus bacteria are common in many non-sterile foods, ie. yogurt, and in the environment. $\underline{\mathrm{S}}$. faecium is commonly found in the intestines of man and animal. The contaminants "represented either non- or low-order pathogenicity and exposure under typical forestry use applications would not likely produce adverse health

effects" (Agriculture Canada letter, Appendix 1). Nevertheless, an informal (not regulated) monitoring system for microcontaminants has been established by companies and monitoring is being done as well 
by Agriculture Canada's Laboratory Services.

The following potential contaminants and acceptable limits are being analyzed for (pers. comm., Glen Dalke, Abbott Laboratories). Salmonella sp.

-zero organisms in $25 \mathrm{gm}$ primary powder

Coliform bacteria

- less than $10^{3}$ organisms/gm powder

Staphylococcus aureus - less than $10^{5}$ organisms/gm powder

Clostridium perfringens - less than $10^{5}$ organisms/gm powder

Pseudomonas aeruginosa - less than $10^{5}$ organisms/gm powder

Streptococci/Enterococci - less than $10^{3}$ organisms/gm powder

\subsection{HOST SPECIFICITY}

In this section, the review will discuss why Btk is host-specific and the susceptibility of various insect groups. The toxicity of Btk to birds, fish, mammals and humans will be discussed elsewhere. Burgerjon and Martouret (1971) provide an early review of the host spectrum of Bacillus thuringiensis. Krieg and Langenbruch (1981) provide detailed information (see pp.841-885) on the relative susceptibility of various invertebrates to different strains of Bt. Btk is shown to be non-toxic to 8 species of coleoptera, slightly toxic to a few species of Diptera (not at operational treatment rates), non-toxic to the ephemeropteran picromerus bedens, non-toxic to any Homoptera or Hemiptera, non-toxic to any Hymenoptera including honeybees, but with significant toxicity to a wide variety of Lepidoptera. Operational field trials indicate that use of Btk enhances natural parasitism (Ticehurst et al. 1982).

The various strains of Bt are also listed as being of zero to low 
The various strains of Bt are also listed as being of zero to low toxicity to Isoptera, Mallophaga, Neuroptera, orthoptera, Thysanoptera and Trichoptera. Krieg and Langenbruch also cite personal unpublished data in this review indicating that Btk is nontoxic to Daphnia sp. and Cyclops sp.

For all practical purposes, at field dosage rates, Btk and its delta-endotoxin affect only Lepidoptera. The specificity of Btk is determined by a variety of factors. The first is that Btk must be ingested before it can kill a susceptible insect. Topical applications of Btk to susceptible species would not result in mortality (Wilkinson et al. 1975). Secondly, in order to release the toxic delta-endotoxin from the protein crystal, the crystal must be exposed to an alkaline $\mathrm{pH}$ of 9.0 to 10.5 and appropriate digestive enzymes (Falcon 1971). This combination of requirements, ingestion, alkaline gut pH, proteolytic enzymes, plus innate susceptibility of the host, restrict the toxic effects of Btk to Lepidoptera. Other strains of Bt do cause mortality in other orders of insects (Heimpel 1967), e.g. Bti to mosquitoes and blackflies and $\underline{B} . \underline{t}$. var thuringiensis to Diptera including house flies. Within the Lepidoptera, there are varying degrees of susceptibility (Heimpel 1967). Highly susceptible Lepidoptera, e.g. Bombyx mori, are classified as Type 1 insects. In these insects, deltaendotoxins cause a rapid paralysis and change in gut pH. Most Lepidoptera belong to the Type II group. These insects suffer rapid gut paralysis, but there is no gut leakage, so these insects starve and die due to septicemia. Type III insects require both delta- 
endotoxin and endospores to cause death (see Heimpel 1967, p. 298). In addition, under operational field conditions, mortality of target insects, e.g. jackpine budworm, varies between trials but rarely exceeds $90 \%$ mortality (e.g. jackpine budworm - 71\% mortality) (Cadogan et al. 1986). Detailed data on the effects due to Btk on non-target Lepidoptera were not found. It is expected that approximately $10 \%$ of the Btk droplets would reach understory vegetation (pers. comm. Nick payne and Terry Innis, Forest Pest Management Institute, Sault ste. Marie). This reduced amount reaching lower foliage would likely result in reduced mortality. Research at the Forest Pest Management Institute ( $K$. Barber) has been initiated to answer the question of non-target Lepidoptera mortality, but data is still pending.

\subsection{MODE OF ACTION}

The primary mechanism by which Bacillus thuringiensis kills insects is a combination of the delta-endotoxin associated with crystals and potentially vegetative growth and septicemia in larvae. Mortality is normally caused by toxins associated with the parasporal crystal and to a limited extent, the endospores. Fast (1977) showed that in spruce budworm (Choristoneura fumiferana), spores enhanced the toxicity of crystals two-fold. However, Fast (1977) concluded that "spores play little or no role in mortality of spruce budworm induced by Bacillus thuringiensis insecticide", i.e. Btk. With other strains of Bt, both spores and crystals are required to cause mortality (Burges et al. 1976). Fast (1976) found the $\mathrm{LD}_{50}$ dose for 
newly moulted 6 th instar spruce budworm to be 0.6 IU or 1280 crystals and the $\mathrm{LD}_{90}$ dose to be 3.5 IU or 7000 crystals. Application of Btk does not result in natural epizootics of target insects, nor does it control larvae in years subsequent to application although reduced defoliation in following years has been noted (Dimond and spies 1981). Increased development time, debility, decreased pupal weights, reduced fecundity, fertility and adult life span of survivors, has been suggested as possible mechanisms to explain the few carry-over effects noted in nature (Morris and Hildebrand 1974).

The chemical structure of the toxin(s) which are derived from Btk have not been defined. This prevents analysis of formulation on an analytical chemistry basis and requires that potency be determined on a bioassay basis and residues on a microbiological basis.

The various toxins found in strains of Bt are proteins. Commercial formulation of Btk contain the protein crystal and endospores with the primary toxin being delta-endotoxin, associated with the protein crystal.

other toxins include alpha-exotoxin. This toxin is found in the supernatants of some Bt fermentations. It is water-soluble and heat-labile. It is produced by bacteria other than $\underline{B} . \underline{t}$. This material is toxic if fed to mice and has been called the mouse factor or thermosensitive toxin (Kreig 1971). Since commercial formulations are spun dry and heat-treated, alpha-exotoxin is not considered of significance in commercial formulations.

Beta-exotoxin is a water-soluble, heat-stable protein that is highly 
toxic to Diptera. Many of the original insecticide formulations of Bacillus thuringiensis var. thuringiensis contained beta-exotoxin. synonyms for this toxin include "fly knock-down factor" or Mcconnell-Richards factor, and thuringiensin (Dubois and Lewis 1981). Beta-exotoxin is toxic to vertebrates and can cause teratogenic effects in insects (Sebesta et al. 1981). Regulatory authorities in Canada and the United States have banned the use of formulations containing beta-exotoxins since 1971. Products containing beta-exotoxins are still used in Europe and the soviet Union. Toxicity data to non-target organisms published in scientific literature prior to 1971 generally refer to Bt strains containing beta-exotoxin. These data, although not directly related to Btk, would represent toxicities more potent than the modern Btk strain which does not contain beta-exotoxin.

The louse-factor is an exotoxin reported by Gingric et al. (1974) as being pathogenic to biting lice, and was derived from Btk HD-1 strain. Its significance in modern formulations of Bt is considered minor and little work has been published on this toxin.

The principal insecticidal component of modern Bacillus thuringiensis formulations is the delta-endotoxin associated with the protein crystal. The crystal itself is not toxic until it is dissolved in vitro under specific conditions or in the midgut of the larvae. The toxic protein is relatively small, between 50-100,000 daltons. In spray programs, Btk is not toxic unless ingested by larvae. Three factors influence the potency of delta-endotoxin: 1) the strain-related origin of the toxin. 2) the degree of solubility 
in the gut juice, and 3) the intrinsic susceptibility of the insect to the toxin (Jaquet et al. 1987).

The toxic protein is insoluble at acidic or neutral pH, but is soluble at alkaline $\mathrm{pH}$. The most susceptible insects are those having a gut $\mathrm{pH}$ of 9.0 to 10.5 and appropriate enzymes to dissolve the crystals (Falcon 1971). It is essentially only Lepidoptera larvae which have this combination of digestive enzymes and alkaline $\mathrm{pH}$.

The toxin once released acts at the surface of the gut epithelial cells to cause a rapid loss (within 5 minutes of feeding) of ATP from cells stimulating respiration and glucose uptake. Within minutes, microvilli of the gut swell and cell apices swell into the gut lumen. Feeding is inhibited within as little as 2 minutes after feeding.

Metabolic breakdown of epithelial cells is complete within 10-15 minutes and ions leak from gut lumen to haemolymph. Paralysis and/or death results from ionic imbalance in the haemolymph. Often changes in gut and haemolymph permit vegetative propagation of gut microbial flora and Bacillus thuringiensis resulting in septicemia which can cause death of larvae in 24-48 hours.

Dependent on susceptibility of larvae and amount of Btk ingested, death may be due to ionic imbalances, caused by the toxin due to disruption of the gut, or by septicemia due to vegetative growth of Btk and or other gut microflora. The susceptibility to Btk is related to the age and biomass of the insect. Younger larvae are generally more susceptible (see Fast 1981 for detailed description). 
At sub-lethal doses, anorexia does occur but recovery from feeding inhibition can occur in 8 hours or less (Retnakaran et al. 1983). There is no evidence of resistance developing to Btk by forest insects although laboratory selection of stored product Lepidoptera have resulted in increased tolerance.

\subsection{MUTAGENICITY}

Being a living organism, the potential exists for mutagenic changes in Btk. The fact that there are over 20 recognized subtypes and 800 strains (Dulmage and Cooperators 1981) indicates that genetic variability exists. With the advances of modern molecular biology, there is, and will continue to be efforts made to isolate and create more potent strains of Btk (Faust and Bulla 1982). All modern registered formulations contain "natural" isolates of Btk and there are no "genetically-engineered" products available. Salama et al. (1984) selected for UV resistant, high temperature resistant, and antibiotic resistant strains of Btk. The selection of UV resistant individuals after 4 minutes exposure to UV light was $0.001-0.2 \%$ dependent on strain. Heat selection at $75^{\circ} \mathrm{C}$ for 120 minutes yielded $0.02 \%$ and $0.16 \%$ mutant survival. Similar low yields of penicillin, streptomycin and chloramphenicol resistant mutants was obtained. What is the possibility that strains pathogenic to vertebrates or other non-target organisms would develop? Bacillus thuringiensis is closely related to Bacillus cereus which has chemical affinities to Bacillus anthrax. The probability of mutations affecting noninsect organisms is exceedingly small. In all laboratory toxicity 
studies done to date, there was no evidence of vegetative growth in non-insect lines (Burges 1981). Each batch of Btk produced by commercial companies is quality checked by injection of a million spores into mice (see Production). Fisher and Rosner (1959) attempted to induce harmful mutations by serial passage of Bt in mammals. There was no increase in virulence to mammals. Steinhaus (1959) considered that the chances of mutation of Bacillus thuringiensis to an anthrax-like organism "are exceedingly small". Forsberg (1976) appears to agree with this conclusion.

Pathogenic mutations of Bacillus thuringiensis are rare, as natural epizootics do not occur in nature or in years following spray programs. Btk appears to be specially adapted to insects, and poorly competitive against other microbes. The lack of widespread natural epizootics would indicate that it is genetically a relatively stable organism with little chance of non-insect infection.

\subsection{SPRAYING/APPLICATION PRACTICES}

Bacillus thuringiensis var. kurstaki is registered in Canada for control of a variety of lepidopterous larvae. Uses include not only protection of forest trees, but protection of a variety of vegetables, e.g. cabbages, brussel sprouts. Domestic class registrations for use by home owners also exist, as do use patterns for municipal parks and urban areas.

For forestry pests, typical target insects, application timing, and 
application rates are outlined in Appendix 2. In forestry management in ontario, the three major pests currently being controlled by Btk are 1) Spruce budworm (Choristoneura fumiferana) 2) Jackpine budworm (Choristoneura pinus pinus) and 3) Gypsy moth (Lymantria dispar) (Appendix 2). Since 1980, a total of 1.23 milion hectares of forest lands have been protected in ontario using Btk products (2.1 million litres) (Appendix 2). Control of spruce budworm and jackpine budworm normally occurs in commercial forestry tracts not associated with human habitation. Control of gypsy moth may include recreational areas and farm woodlots primarily in eastern ontario, but with expanding range into other areas of southern ontario, i.e. Simcoe.

control of lepidopterous larvae is intended to protect trees from defoliation. Larvae must ingest Btk crystals. Consequently, all programs are timed to treat trees while larvae are mid-instars and openly feeding on foliage (Table 2). For spruce budworm, spraying is done soon after bud flush before larvae reach fifth instar. Similarly, jackpine budworm is treated after needle pairs begin escaping from sheaths. Gypsy moth larvae are treated when $40-50 \%$ leaf expansion (typically oaks) occurs and before larvae reach third instar. In ontario, application times will vary somewhat with the phenological development of trees and target insect, but essentially all spray programs for control of major pests will take place between mid-May and the first week of July.

Most forestry applications of Btk in ontario will be applied aerially under contract to the Ministry of Natural Resources. 
Table 2. Forestry uses for Btk in Canada (from Thuricide 48 LV Label)

$\begin{array}{lllll}\text { Pest } & \text { Crop } & \text { Timing } & \text { BIU } & \text { Litres/ha } \\ \text { Bagworm } & \begin{array}{l}\text { Ornamentals } \\ \text { Shade trees }\end{array} & \begin{array}{l}\text { when larvae } \\ \text { feeding }\end{array} & 13-19 & 1-1.5 \\ \begin{array}{l}\text { Elm/Fall } \\ \text { spanworm }\end{array} & \text { Hardwoods } & \begin{array}{l}\text { after leaf } \\ \text { flush }\end{array} & 9-19 & 0.7-1.5 \\ \begin{array}{l}\text { Gypsy moth } \\ \text { Forest trees }\end{array} & \begin{array}{l}\text { 40-508 leaf } \\ \text { expansion }\end{array} & 20-30 & 1.6-2.4 \\ \begin{array}{l}\text { Spring/Fall } \\ \text { cankerworm }\end{array} & \text { Hardwoods } & \begin{array}{l}\text { after leaf } \\ \text { flush in } \\ \text { spring }\end{array} & 6-9 & 0.5-0.7 \\ \begin{array}{l}\text { Spruce } \\ \text { budworm }\end{array} & \text { Conifers } & \begin{array}{l}\text { soon after } \\ \text { bud flush }\end{array} & 15-30 & 1.2-2.4 \\ \begin{array}{l}\text { Jackpine } \\ \text { budworm }\end{array} & \text { Jackpine } & \begin{array}{l}\text { at needle } \\ \text { flush }\end{array} & 30 & 2.4 \\ \begin{array}{l}\text { Tent } \\ \text { caterpillar }\end{array} & \begin{array}{l}\text { Deciduous } \\ \text { trees }\end{array} & \begin{array}{l}\text { at leaf } \\ \text { flush }\end{array} & 6-9 & 0.5-0.7\end{array}$


The Ministry of Natural Resources will have on site a variety of personnel including application supervisors, safety and communication personnel. The current applications supervisor is Craig Howard, Natural Resources, Sault ste. Marie (705-759-5727). There are detailed management plans in place for all aerial spray programs (Carrow et al. 1981) including public meetings to outline proposed spray operations. The Ministry of Natural Resources is to be commended for the detailed planning and execution of their spray programs. All aerial applications are restricted to licensed aerial applicators.

The majority of published papers on Btk spray operations deal with control of spruce budworm. Application normally involves the use of fixed wing aircraft or large helicopters (i.e. Cessna Ag-truck, Piper Pawnees, Grumman Ag-Cat and Bell 206 helicopters) (see Morris 1982, Table 3).

The objective of spray application is to thoroughly cover foliage with deposits of Btk. Typically, application is made in the early morning or late evening when winds average less than $10 \mathrm{~km} / \mathrm{hr}$. Aircraft and helicopters make applications from ca. $10 \mathrm{~m}$ above the canopy using conventional boom and nozzle spray systems or Micronair rotary atomizers (Morris 1982, Cadogan et al. 1986). Ideally, material should be applied at droplet sizes of 50-200 microns. Spray deposits of 10-20 droplets $/ \mathrm{cm}^{2}$ are desirable. For the gypsy moth, $\mathrm{LD}_{95}$ levels are $10.8,2.2$ and 0.9 drops per $\mathrm{cm}^{2}$ for 100,200 and 300 micron droplets respectively (Bryant and Yendol 1988). Ideally, conditions should be humid and warm with lepidopterous larvae 
actively feeding. There should be no rain for at least 24 hours after spraying to prevent washing off of spray deposits and ensuring ingestion by larvae.

Typically, treatments are made to provide a coverage of 30 BIU per hectare involving 1-3 litres of product per hectare if undiluted and 2-6 litres per hectare if diluted in water. There is increasing tendency to spray formulations undiluted to reduce application costs. There is a no buffer zone associated with water when spraying with Btk in ontario or other provinces. However, in the public hearing process, efforts will be made to accommodate those with concerns and, for control of gypsy moth, small island cottage sites will not be treated.

Dependent on densities of larvae and success of initial spray, areas may be retreated 5-14 days after initial application. With spruce budworm and jack pine budworm, a second treatment is required in about 5\% of the cases. With the gypsy moth, three treatments spaced approximately one week apart may be required in a small percentage of cases. Most gypsy moth treatments require two treatments due to asynchronous development of larvae. Thus, certain areas i.e. high density infestations of gypsy moth, may have 90 BIU's per hectare applied over a three week period. Success of treatments with modern formulations has generally been satisfactory, providing significant larval mortality of approximately 75\%, and good foliage protection of $>50 \%$. Success of programs has varied and meteorological conditions after spraying probably influence results as well as synchrony in target insect development. Fast and Regniere (1984) 
showed that extending the exposure period from 1 day to an exposure of 6 days resulted in a 500 fold increase in the $\mathrm{LC}_{50}$ of $\mathrm{Btk}$ on spruce budworm larvae. With better formulations, better application technology (i.e. droplet size) and repeat sprays, control has been more consistent than in the past.

\subsection{METHODS FOR ENUMERATING BTK FROM ENVIRONMENTAL SAMPLES}

Since the chemical structure of the delta-endotoxin of Btk has not been determined, monitoring of Btk residues can not be made using analytical chemistry techniques. Enumeration of Btk deposits is done by several methods including 1) deposit sampling at the time of application 2) bioassay procedures of foliage which has been treated 3) microbiological plating techniques and more recently 4) ELISA and immunofluorescence techniques.

Morris (1982, pp. 247-51) describes the various methods for assessing Bt deposits at the time of spray application. One method is placement of a petri plate with nutrient agar amended for Bt growth at various locations in the forest canopy and floor. These collect bacterial droplets as they descend and plates are then incubated for 18 hours at $29^{\circ} \mathrm{C}$ and colonies counted. This method underestimates deposits since any colony may represent 150 viable spores. Deposits can be collected on glass plates, rinsed with distilled water, diluted with $0.1 \%$ peptose water, and serially diluted onto agar media (tryptic soy). This technique was 2,000 times more sensitive than the petri plate method. 
Kromekote cards can be used to analyze spray deposits when Btk formulations contain marker dyes. Droplets can be analyzed microscopically or using image analyzers. Similarly, dyed deposits can be rinsed from glass plates $(1.5 \mathrm{ml}$ of $0.1 \% \mathrm{NaOH}$ ) and eluates measured colormetrically (Cadogan et al. 1986).

The detection and quantification of Btk endospores and vegetative cells from various substrates can be made using various methods involving plating substrates onto appropriate growth media. Reardon and Haissig (1984) simply collected foliage (needles) and made impressions of the foliage into tryptic soy agar media (GBCO, Madison, Wisconsin). Plates were stored at room temperature for 48 hours. Bacillus-like colonies were identified and spore stains (Benz and Boursiewiez 1963) made of random sub-samples. Faust and Bulla (1982 p.94) describe a variety of staining techniques for Bacillus thuringiensis.

Petras and Casida (1985) recovered Btk from soil by placing log samples in a blender with $30 \mathrm{ml}$ of sterile tap water. The material was then serially diluted and $0.1 \mathrm{ml}$ aliquots of various dilutions were spread onto Heart infusion broth-Gelute plates (Kelco, San Diego, California). These were incubated for 1 week at $27^{\prime \prime} \mathrm{C}$. Young Bt colonies were white and thin with a cottony appearance and irregular edge. Bt colonies after 6 days incubation could be checked for spore and crystal formation.

Menon and Mestral (1985) isolated and enumerated Btk from water and shellfish by spread plate method using a nutrient agar containing $4 \mathrm{ppm}$ penicillin and $5 \mathrm{ppm}$ polymixin B sulfate. Plates were 
incubated for 48 hours at $37^{\circ} \mathrm{C}$ and $\mathrm{Btk}$ identified by colony morphology (description not provided). Colonies were confirmed by taking a thin film aqueous suspension of colonies onto a clean slide. This was air dried and heat-fixed. A thin layer of reagent A (Admidoschawartz- $1.5 \mathrm{~g}, 98 \%$ methanol $50 \mathrm{ml}$, acetic acid $10 \mathrm{ml}$ and distilled water $40 \mathrm{ml}$ ) was pipetted onto the smear while still warm. This was rinsed off after 70 seconds. The smear was then covered with zihl's carbol fuchsin for 20 seconds, rinsed in tap water and dried. Stained crystals were lilac blue and endospores pink under dark field, phase contrast microscopy.

In the literature, there are numerous methods of isolating and enumerating $B t k$ from media and the above mentioned simply demonstrate some of the techniques.

The newest method of Btk detection and enumeration is by the ELISA (enzyme-linked immunosorbent assay) technique (Reardon and Hassig 1984) using $\underline{B} . \underline{t}$. kurstaki toxin as the assay. This technique is described as extremely sensitive, accurate and highly specific (Wie et al. 1981). This has a sensitivity of $3 \mathrm{ug} / \mathrm{g}$ ( $3 \mathrm{ppm}$ ) of needle tissue due to interfering cross-reactivity in needle tissue. It is probable that in water, the sensitivity would be greater due to reduced interference. Smith and Ulrich (1983) describe in detail the ELISA technique for detection of the crystal toxin of Btk. West et al. 1984 describe a detection method for Btk in soil using immunofluorescence which compared favourably with bioassay and plating techniques. 


\subsection{ENVIRONMENTAL FATE}

\subsection{Foliage}

Forsberg (1976, Table 3 pp.32-39) summarizes various laboratory studies on the field and laboratory persistence of Bacillus thuringiensis. Similarly, Morris (1982) has summarized the persistence of $\mathrm{Btk}$ on foliage when used in forest applications (Table 3). In general, Btk loses $50 \%$ of its insecticidal activity in 1-3 days, often necessitating a second spray application for insects such as the gypsy moth, spruce budworm and jackpine budworm. In some studies (e.g. McLeod et al. 1983, Beckwith and Stelzer 1987) longer residual activity (i.e. 10 days) has been reported.

Persistence of $\mathrm{Btk}$ on foliage is dependent on many environmental factors. Leong et al. 1980 concluded that sunlight exposure, leaf temperature and vapour pressure deficit contribute most to endospore decay. Sunlight, particularly ultra-violet radiation, inactivates $50 \%$ of Btk cells within 30 minutes and $80 \%$ within 60 minutes (Krieg 1975).

The inactivation of both spores and crystals is believed due to production of peroxide or peroxide radicals produced by UV irradiation of amino acids (Ignoffo and Garcia 1978). In situations where prolonged activity of Btk has been reported (i.e. McLeod et al. 1983) persistence is believed due to deposits in cracks and crevices protected from direct sunlight. Some viable endospores of Btk have been recovered from foliage after ground application of Btk (1 BIU/tree) one year after treatment (Reardon and Haissig 1984). 


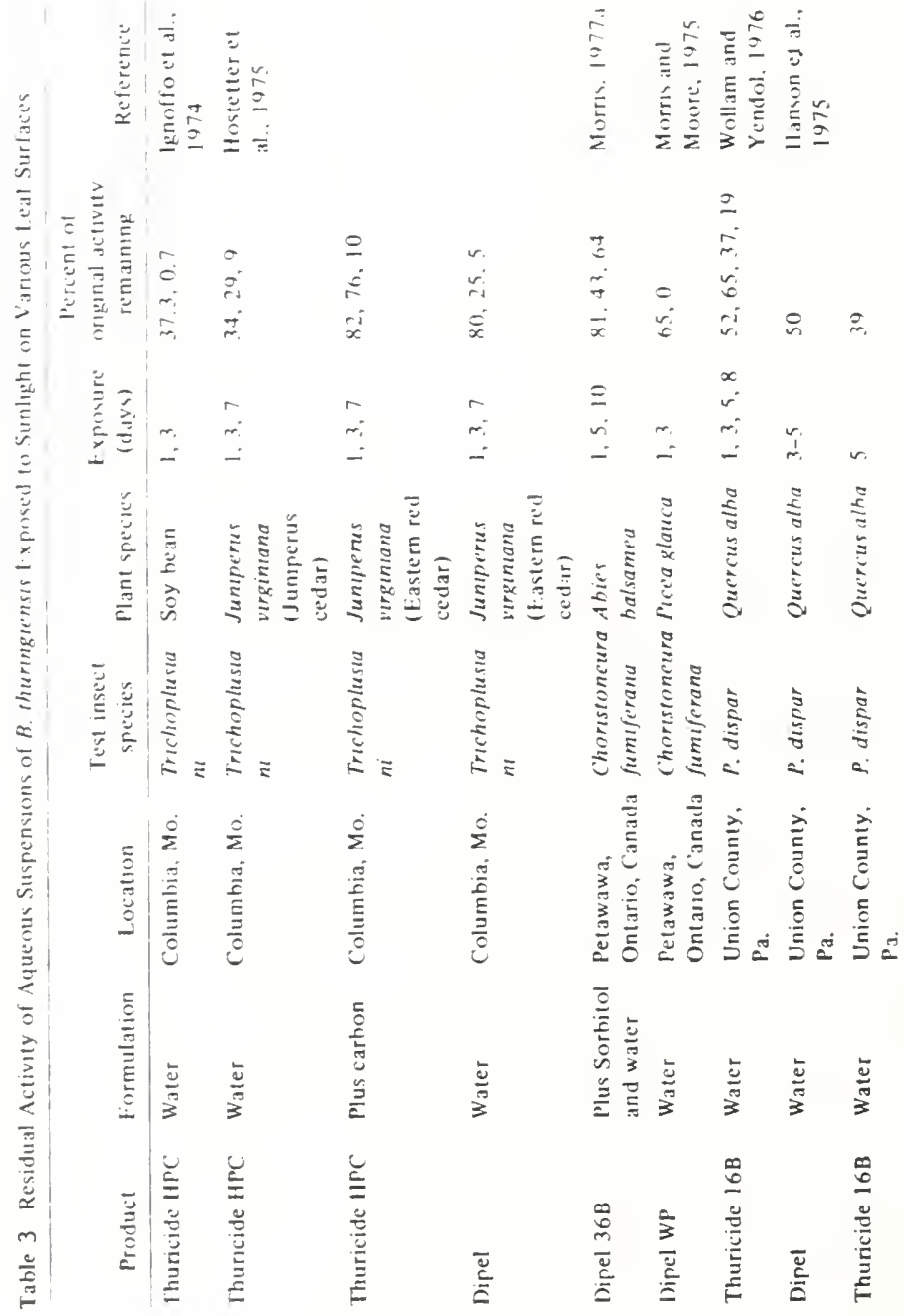




\subsection{Soil}

An excellent review of the fate of Bacillus thuringiensis in soil is provided by Dulmage and Aizawa (1982). They concluded that Bt as applied to ecosystems will persist for several months in the soil. Bacillus thuringiensis can survive as endospores in most types of soil (Saleh et al. 1970) although at pH below 4.8, Bt will not grow. Repeated applications of Bt results in no increased accumulation of the organism (Dulmage and Aizawa 1982, p.223). There appears to be a maximum carrying capacity in most soils.

The fate of Bt in soil is dependent on microbial competition. In unsterilized soils, numbers of Btk rapidly diminish but may increase in sterilized soils (Akiba et al. 1977). When soil was treated at $10^{5}$ cells per gram, Bt persisted at $10^{3}$ cells/g for $12-16$ months. However, the relative number of Bt compared to other soil bacilli was reduced from $20-40 \%$ to about $10 \%$ indicating that $B t$ is not welladapted to soil environments. Delucca et al. (1981) showed that Bt does not move in the soil, as two serotypes sprayed in close proximity did not become cross-contaminated. Pruett et al. (1980) have shown that in soil, although $38 \%$ of the endospores remained viable after 63 days, only 3\% insecticidal activity remained; after 135 days, there were $23 \%$ of the original spores and no insecticidal activity. This strongly suggests that delta-endotoxin decays far more rapidly than endospores. Finally, west et al. (1984) have shown that Bt will not grow (i.e. vegetative growth) under most natural soil conditions, emphasizing that it is not a well adapted 
member of the soil microbial community, but requires specialized habitat of insect bodies.

\subsection{Water}

Menon and Mestral (1985) reported that after Btk operational spray programs in Nova Scotia (4.7-9.4 L/ha of Thuricide 16B), Btk could be found in stream and reservoir water for 8-12 days after spraying. Laboratory studies with high inoculation $\left(10^{4}\right.$ cells/ml) indicated approximately $30 \%$ survival of Btk after 70 days in distilled and tap water (Fig.2). In lake water, approximately 50\% of cells remained viable after 70 days. Better survival in lake water is believed due to the presence of nutrients. In sea water, less than $10 \%$ of Btr: cells survived after 40 days. Although viable spores were found in the study by Menon and Mestral (1985) and colony counts were confirmed by identification of parasporal bodies, parasporal endotoxin activity against Lepidoptera was not evaluated. Since water was sterilized and kept in the dark, two major decomposition factors, UV radiation and microbial degradation, did not occur. These survival levels thus represent levels unlikely to occur in the field, especially when considering steams and shallow lakes. Menon and Mestral (1985) also reported that Btk was resistant to chlorination at low concentrations of 0.1 to $0.5 \mathrm{mg} / \mathrm{L}$.

Buckner et al. (1974) found that samples of river water 30 minutes after spraying contained 1730 spores per ml, one month later, no spores were found. 


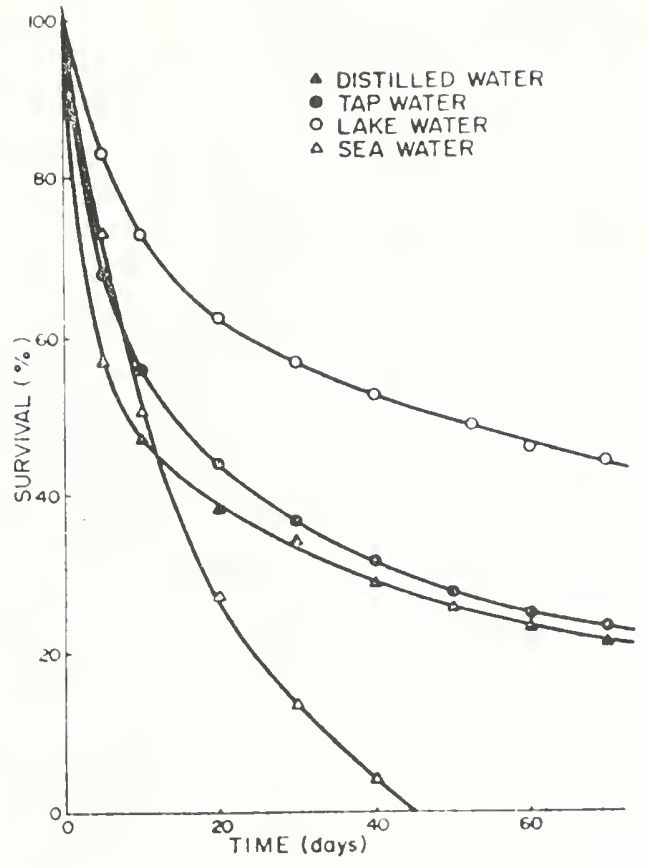

Fig. 2. Survival of B.t. var. kurstaki in distilled water, tap water, lake water and sea water at $20^{\circ} \mathrm{C}$ (Menon and Mestral 1985). 


\subsection{AQUATIC TOXICITY}

\subsection{Expected Exposure Levels}

In forest spray operations, it is expected that approximately 30 BIU (Billion International Units) of toxicity will be applied per hectare. The proposed worst case scenario for Btk concentrations in water is believed to be equivalent to approximately $2.14 \mathrm{IU} / \mathrm{ml}$ of water or 2,140 IU per litre (Eidt 1985). This figure was derived by comparing amounts of active ingredient, i.e. permethrin, fenitrothion, entering aquatic systems during operational and experimental spray programs. Similarly, if one assumes direct application to a hectare of water a meter deep, there would be a concentration of 3 IU per ml of water. Depending on the formulation of Btk used, this would represent extremely low volumes of material, for example, if $2.4 \mathrm{~L}$ of $\operatorname{Dipel}^{\mathrm{R}} 132$ were applied to a hectare of water with a mean depth of 1 metre, this would represent 0.24 ul of product per litre. If spraying is repeated 7-10 days after initial application, it is unlikely that there would be accumulation of Btk due to stream flow and rapid inactivation of Btk by microorganisms.

\subsection{Fish Toxicity}

In reviewing the toxicity of Bt to fish, Forsberg (1976 - pg.52) cites several studies with older formulations of Bt and gives toxicity values. All of these trials report results of non-Btk strains which presumably contained beta-exotoxins. Tests did not specify toxicity levels (i.e. IU) of Bt formulations. They have 
little value in the current review of Btk other than to provide bench marks of toxicity which are probably greater than those of Btk which does not contain beta-exotoxin.

Few published scientific papers on Btk toxicity to fish which pertain to modern formulations were found. According to Ignoffo (1973), little or no effects were observed when rainbow trout, yellow perch, mosquito fish, or black bullhead fingerlings were exposed for 4 days to $4.5-65 \times 10^{4}$ spores $/ \mathrm{ml}$. Effects that were probably due to the petroleum carrier occurred at doses greater than $6 \times 10^{7}$ spores/ml. Some juvenile coho salmon died at the high dose when they were exposed for 7 days to doses ranging from $5.2 \times 10$ to $26.4 \times 10^{9}$ spores $/ \mathrm{ml}$. Buckner et al. (1974) reports concentrations of spores in river water 30 minutes after treatment as 1,730 per ml, indicating that laboratory toxicities were typically 1,000 fold higher than field concentrations. Studies cited by Forsberg (1976, pg. 63-64) refer to Bt formulations which probably contain betaexotoxins. Typically, the studies reported no mortalities or LC. values of formulated product Thuricide at $600 \mathrm{ppm}$ or greater. Since these formulations would contain the beta-exotoxins which are more toxic to vertebrates, they represent toxicities significantly greater than those of modern Btk formulations which contain no betaexotoxin. It appears that solvents and emulsifiers would be more toxic than the active ingredient. Potency of formulations was not reported.

Todd and Jackson (1961) found no adverse effects on coho salmon fry or on aquatic insects using formulations of Bt. Buckner et al. 1974 
evaluated the aquatic impact of Thuricide $16 \mathrm{~B}$ at the rate of ca. 17.6 BIU per hectare in Algonquin Park, ontario. They reported that fish, i.e. brook trout (Salvelinus fontinalis), white suckers (Catostomus commersoni) and small mouth bass (Micropterus dolomieui) and bottom fauna populations (wide variety of organisms) in rivers suffered no adverse effects up to four weeks after treatment. Viable Bt spores were present in river water (1,730 spores/ml) and clams immediately after treatment, but disappeared in four weeks. spores were not detected in crayfish collected from the river (Buckner et all. 1974).

Proprietary studies on the various formulations exist in the Pesticides Directorate, ottawa. These studies have been reviewed by Fisheries and Ocean personnel, and Environment personnel. The studies met with approval of these ministries. The lack of any documented fish kills in any of the forestry or agricultural spray programs involving Btk across canada and the United states may be the most valid argument for fish safety. Since the mid 1970's, several million hectares of coniferous forest have been sprayed for spruce budworm and jack pine budworm and several hundred thousand hectares for the gypsy moth ( $\underline{L}$. dispar). There is no evidence of fish kill in any trials. In ontario, there has been approximately 1.3 million hectares of forest lands sprayed with Bt between $1980-$ 1987 (Churcher, pers. comm.), and to our knowledge, no fish effects have been reported.

In examining fish toxicity, an additional indication of lack of toxicity with Btk and toxicity of emulsifiers is reflected in 
published toxicity studies of the closely related Bacillus thuringiensis var. israeliensis (Bti). In Quebec, Fortin et al. (1986) showed that at extremely high concentrations $(4,500$ to 6,000 $\mathrm{mg} / \mathrm{L}$ ) of formulated Bti (Tecknar ${ }^{\mathrm{R}}$, mortality of brook trout (Salvelinus fontinalis) was 20 and $86.4 \%$ respectively. However, fish exposed to $6,000 \mathrm{mg}$ of freeze-dried Tecknar were not affected. Fish fed for $48 \mathrm{~h}$ with chow contaminated with $30 \% \mathrm{~W} / \mathrm{W}$ Tecknar did not show any response. The authors concluded that mortality at high concentrations with liquid formulation was due to $2 \%$ xylene which was used as a preservative in the formulation. (It should be noted that no Btk forestry product currently contain xylene).

Forsberg (1976, pg. 52) suggested that the primary route of exposure of Btk to fish may be through ingestion of spruce budworm larvae falling into the stream. His concern was the sensitivity of fish to Btk vegetative cells. The study by Fortin et al. 1986 where fish were exposed to $30 \% \mathrm{~W} / \mathrm{W}$ formulated Bti may alleviate some of this concern. If vegetative cells adversely affect fish to any significant degree, this would have become apparent in widespread forestry spray programs already conducted.

Impact studies of Bt on six species of fish carried out by Buckner et al. (1974) in Canadian spruce-fir forests, revealed no abnormal effects 3 days and 1 month after spray application.

\subsection{Aquatic Invertebrates}

Although there is no suggestion of direct mortality to fish, an expressed concern has been the potential effects of Btk on fish 
through effects on their food organisms, most important of which are aquatic insects. Eidt (1985) evaluated the toxicity of Btk to aquatic insects using the commercial formulation of Thuricide $32 \mathrm{LV}$ containing $8.45 \mathrm{BIU} / \mathrm{L}$.

Insect immatures were exposed to concentrations of $4.3,43$, and 430 $I U / \mathrm{ml}$. This represented 2,20 and 200 times the expected maximum field exposure. Immatures were maintained in $300 \mathrm{ml}$ of water, and air was bubbled into those jars containing stream insects to provide aeration and circulation. The appropriate concentrations of Bt: were added to water after $24 \mathrm{~h}$ and immatures were then treated with the appropriate concentrations of Btk. It should be emphasized that immatures were maintained with Btk for ca. 15 days, whereas in field situations, maximum pesticide exposure would be for less than 6 hours and rare after 24 hours (Poirier and Surgeoner 1988). The results of Eidt's (1985) toxicity evaluations are summarized in Table 4.

The conclusions of the study by Eidt 1985 were as follows: "There is no hazard of Btk. aerial sprays at rates adequate for sprucebudworm control to fish-food organisms in streams. Deposits in shallow ponds are of little concern in New Brunswick, and measurable hazard to non-target organisms is unlikely, with the possible exception of mosquito larvae and related insects with similar feeding strategies. Subsequent to these experiments, in May 1984, the New Brunswick regulations were changed so that buffer zones were not required around water bodies for aerial spraying with Btk." 
Table 4. Effects of Btk (Thuricide 32LV) on Representative Aquatic Insect Fauna (Eidt 1985).

$\underline{\text { Taxa }}$

\section{Prosimulium \\ fuscum/mixtum \\ (Simuliidae) \\ Simulium vittatum \\ (Simuliidae)}

Hydropsyche

(Trichoptera: Hydropsychidae) water.

Chimarra

(Trichoptera: Philopotamidae)

Tanytarsus

(Chironomidae)

Procladius ruris

(Chironomidae)

Stoneflies

(Plecoptera)

Leptophlebia

(Ephemeroptera: Leptophlebiidae)

Nigronia serricornis

(Megaloptera: Corydalidae)

\section{Effect}

-some impact suggested. -high mortality after 5 days for all concentrations and control.

-effects at $430 \mathrm{IU} / \mathrm{ml}$ (758

mortality).

- no effect at lower dosages.

- no effect.

- better survival in treated

-any effect unlikely.

-possible impact at $430 \mathrm{IU} / \mathrm{ml}$.

- no effect.

- best survival at highest concentration.

- no effect.

- no effect.

- no effect. 
Buckner et al. (1974) in monitoring programs of a stream in Algonquin Park where the forest was treated with 17.6 BIU of Thuricide also found that Btk had no measurable effect on Trichoptera (caddisflies), Ephemeroptera (mayflies), Plecoptera (stoneflies), Odonata (dragonflies), Coleoptera (water beetles) and Diptera (flies). These authors also found no effect to Turbellaria (planaria, flatworms), Nematoda (nematodes, roundworms), Olighochaeta (earthworms), Hirudinea (leeches), Amphipoda (crustaceans), Decapoda (crayfish), Hydracarina (water mites), Gastropoda (snails), and Pelecypoda (clams, mussels). Survivorship of crayfish and clams kept in baskets in spray and non-spray plots was not significantly different.

In a study by Menon and Mestral (1985), shellfish were collected from two experimental spray sites in Nova Scotia treated in June. The Btk formulation used was Thuricide 16 B $(0.34 \%$ Btk, $48.15 \%$ culture medium, $1.5 \%$ xylene, $0.01 \%$ Chevron sticker and $49.99 \%$ water) at rates of $4.7-9.4 \mathrm{~L} / \mathrm{ha}$ Btk enumeration of shellfish samples was based on colony morphology (using nutrient-polymyxin-penicillin agar plates) and microscopic examination of stained smears of all suspected colonies for parasporal crystals. No Btk was recovered from any of the shellfish examined. Morris (1982) cites a paper by Feng (1966, J. Invert. Pathol. 23:280-4) indicating no effect to American oysters despite high exposure to Bt. He also cites Alzieu et al. (1975) who found no effect to shrimp, mussels, oysters and periwinkles (Sci. Peche Bull. Inst. Peche Maut. \#250 pp. 11-18). 
Krieg and Langenbruch (1981) cite unpublished data indicating that Btk is not toxic to cyclops $\mathrm{sp}$. or Daphnia $\mathrm{sp}$.

\subsection{HEALTH EFFECTS (TO HUMANS)}

Samples and Buettner (1983) report on a corneal ulcer apparentiy caused by Btk when formulated suspension was accidentally splashed into the eye of a farm worker. Despite widespread usage throughout the world (e.g. 1 million pounds annually in the U.S.A.), this is the only reported infection in humans or other vertebrates. Warren et al. (1984) report on a laboratory worker who developed infection after injection of Bacillus thuringiensis var. israeliensis and Actinobacter calcoaceticus into his finger. In both cases, antibiotic treatment resulted in complete recovery.

Heimpel (1971) cites a study by Fisher and Rosner (1959) where eighteen volunteers ingested 19 of Thuricide $^{R} /$ day for 5 days, at a concentration of $3 \times 10^{\circ} \mathrm{viable}$ spores $/ \mathrm{g}$. In addition, 5 of the test subjects inhaled $100 \mathrm{mg}$ of the powder daily for 5 days. All subjects were then thoroughly examined and again 4-5 weeks later. All people tested remained healthy and all the extensive laboratory tests were negative. In addition, there are records of eight employees who were exposed to the bacterial preparation during the course of product manufacturing. The exposure periods totaled 25 hours in some cases with the result that all exposed personnel were in good health and showed no harm from the exposure. 


\subsection{EFFECTS ON NON-TARGET TERRESTRIAL ANIMALS}

\subsection{Insects}

A valid concern when dealing with an insect pathogen such as Btk is whether or not it will harm beneficial insects. From the literature available, it is evident that $B t$ is safe for beneficial insects. A number of studies have dealt with this topic, and several of them are summarized here.

Work done by Hassan et al. (1983) concluded that Dipelk (Btk) was harmless to most of the beneficial arthropods tested, i.e. Trichogramma, Pales, Phygadeuon, Leptomastix, Coccygminus, Chrysopa, Encarsia, Amblyseius, and was only slightly harmful to syrphus. Evaluation was carried out by measuring the reduction in beneficial capacity (i.e. parasitism) or performance (i.e. egglaying) compared to the controls. It was concluded that $\mathrm{Dipel}^{R}$ can be recommended for use in integrated control programs. Another study by Wilkinson et al. (1975) demonstrated that Btk (Thuricide HPC $^{\circ}$ ) applied at the minimum recommended field dose has little or no effect on parasitoids such as chalcids, ichneumonids, braconids and tachinids, or on predators such as chrysopids and coccinelids. Buckner et al. (1974) reported no effect on parasites of the spruce budworm.

other studies by Dunbar and Johnson (1975) showed that Btk (Dipel'WP 16,000 IUP/mg and Biotrol ${ }^{8} \mathrm{XK}$, WP 7,500 IUP/mg) decreased posttreatment longevity of Cardiochiles nigriceps (a tobacco budworm parasitoid) when ingested as dissolved active ingredient in sugar water. The authors are quick to point out, however, that these 
parasites probably would not feed on Btk in the field, and only fed on it in the laboratory since the sugar acted as an attractant. When $\underline{c}$. nigriceps adults were topically treated with Btk, no difference occurred in post-treatment longevity between untreated and Dipel ${ }^{R}$-treated wasps. Also, wasps exposed to tobacco leaves treated with Dipel were not affected.

Tipping and Burbutis (1983) studied the effect of Btk (Thuricide, $4,000 \mathrm{IU} / \mathrm{mg})$ residues on adult emergence and parasitism of the egg parasitoid Trichogramma nubilale. Tests were conducted on 1-, 7-, 14- and 21-day greenhouse spray residues from pepper plants at 2 dosage rates, i.e. $9.8 \times 10^{\circ} \mathrm{IU}$ of $\mathrm{AI} / \mathrm{ha}$ (recommended dose) and 1.96 $\mathrm{X} 10^{\circ} \mathrm{IU}$ of $\mathrm{AI} / \mathrm{ha}$. Btk was found not to reduce emergence from, or parasitism of, European corn borer.

To determine the effects of Bt on natural enemies of western spruce budworm, parasite studies were conducted by Niwa et al. (1987) during field tests of two Btk formulations (San-415 and Thuricide $32 \mathrm{LV})$ applied at 2 dosages $(20$ and $30 \mathrm{BIU} / \mathrm{ha})$ against western spruce budworm in oregon. Microscopic examination showed that three parasitic species contained Btk, namely Glypta fumiferanae, Apanteles fumiferanae, and phytodietus fumiferanae. Occurrence of parasites infected or contaminated with Bt was extremely low $(37 / 3000)$ and did not seem to be related to any of the treatment applications. Infected parasites matured sufficiently to exit from their hosts, but were not able to complete development. It is possible that premature parasite mortality was due to insufficient nutrition caused by the early deaths of their hosts, rather than by 
microbial infection. In addition, there was no significant difference between total parasitism, nor the species distribution of the parasite complex, between the control and the sprayed plots during any of the sample periods. Despite the fact that Btk may affect a small number of parasites developing within infected hosts, it was concluded that field application of Btk for control of western spruce budworm would not be detrimental to the associated parasite complex.

Studies by Haverty (1982) have concentrated on evaluating the effect of the carrier of Dipel $4 L^{k}$ against non-target insects i.e. the common green lacewing (Chrysopa carnea), the convergent lady beetle (Hippodamia convergens) and an aphelinid (Aphytis melinus). Three aerosol spray treatments were evaluated: 1) water only, 2) Dipel* carrier and water (1:3) at $9.4 \mathrm{~L} / \mathrm{ha}$ and 3) Dipel ${ }^{\mathrm{F}}$ carrier and water (1:3) at $18.7 \mathrm{~L} / \mathrm{ha}$. The concentrations of the 2 treatments selected were representative of the optimal maximum rates of Dipel $4 \mathrm{~L}$ aerially applied in forests for the control of spruce budworm and western spruce budworm. The $9.4 \mathrm{~L} /$ ha rate did not result in a significant increase in mortality (never exceeded $2.1 \%$ ) for any species tested up to 7 days post-spray. The $18.7 \mathrm{~L} /$ ha rate resulted in a significant increase in mortality for $\underline{C}$. carnea and $\underline{H}$. convergens adults $3-7$ days after treatment (although mortality never exceeded $13.4 \%$ for any species). The amount of formulation that actually reached test insects in the experimental spray chamber used was estimated at 4-8 times greater (depending on dose) than that which would be expected to reach insects when applied in a forest. 
These experiments suggest that the carrier in Dipel $4 L^{R}$ could cause slight increases in mortality of non-target insects, but only when applied in excessive amounts. It was concluded that any potential disadvantages for increased mortality are outweighed by the benefits of having a microbial insecticide such as Bt for control of forest defoliators.

Buckner et al. (1974) reported no dramatic reduction of non-target insects on any of the Algonquin Park areas treated with Btk (see aquatic toxicity section).

Many studies on the effect of Bt on honey bees (Apis mellifera) have been undertaken and are summarized in Bailey (1971). The overall conclusion of these studies is that there is no evidence that bees will be harmed by Btk in practice. According to Atkins et al. (1975), Btk was non-toxic to honeybees at levels as high as 726,000 spores/bee. Buckner et al. (1974), working in Algonquin Park with 7 honeybee colonies in an operational experimental program involving Dipel concluded "There was no evidence from the data collected that any of the Bt formulations affected domestic honeybee colonies, even when the entire foraging area was treated."

\subsection{Earthworms}

To test the effect of Btk on earthworms, Benz and Altwegg (1975) applied Dipel D $^{R}(16,000$ IU of potency (IUP/mg) in 3 concentrations: 60,600 and $6,000 \mathrm{mg} / \mathrm{m}^{2}$ on field plots measuring $9 \mathrm{~m}^{2}$ (recommended dose for field application $=60 \mathrm{mg} / \mathrm{m}^{2}$ ). Before treatment, a $50 \mathrm{~cm}$ square $(30 \mathrm{~cm}$ deep) was dug out and all earthworms counted. After 
3, 6 and 9 weeks, other $50 \mathrm{~cm}$ squares were dug out on the plots and the earthworms counted and examined for signs of disease. There was no significant difference in worm density between untreated and Bttreated plots demonstrating that field treatments using normal concentrations of $\mathrm{Dipe}^{R}$ would have no adverse effect on earthworm populations.

\subsection{Birds}

There were no significant reductions in bird populations (74 species representing 21 families) apparent in areas treated with Btk with and without chitinase in Canadian spruce-fir forest treatment plots, located in Spruce Woods, Manitoba and Algonquin Park, Ontario (Buckner et al. 1974). Ignoffo (1973, p. 152) cites several studies (primarily with old Bt formulations) indicating that Bt had no effect on pheasants, partridge, cornish hens or chickens at high levels in the diet, e.g. $0.2-570 \times 10^{7}$ spores/bird/day for 28-70 days.

Forsberg (1976) cites unpublished reports provided by Abbott Laboratories to the NRC committee indicating that $250 \times 10^{\circ}$ spores of $\mathrm{Btk} / \mathrm{kg}$ body weight, orally administered for 21 days, caused no mortality or weight reductions in quail (stephens 1970, see Forsberg 1976, p. 69). Twelve pullets fed $38 \times 10^{9}$ spores/kg for 14 days showed reduced weight gains but no mortality (Couch 1973, cited by Forsberg 1976). Smirnoff and MacLeod (1961) administered $0.25 \mathrm{ml}$ of $3 \times 10^{9}$ spores/ml daily to juncos, sparrows and starlings by syringe for 2 weeks. There was no mortality, weight loss or change 
in appearance to birds. Bacteria could be detected in faeces for up to 4 days after feeding had been discontinued.

The possibility of indirect effects to birds due to reduced food availability has been raised. Szuba et al. (1988, unpublished data) from the University of Toronto indicate increased mortality (approximately 30\%) of spruce grouse chicks in Jackpine plots treated with Btk. This is believed due to reduced Lepidoptera numbers. It was shown, however, that the year after spray, mating pairs of spruce grouse were not significantly different from the year before.

\subsection{Mammals}

According to Heimpel (1971), most of the initial experimental work carried out on the safety of Bt has been done by Fisher and Rosner (1959) using the product Thuricider, at a concentration of $9 \times 10$ viable spores/g, a product which would have contained beta-exotoxin. Results are summarized as follows:

1) Virulence of Thuricide following serial passage through mice. Mice injected intraperitoneally with Thuricide had blood taken 6 hours later by cardiac puncture. This was injected intraperitoneally into a second group of mice and serial passage repeated with 5 more groups of mice and none of the terminal group showed abnormal symptoms.

b) Persistence of B.t. in blood of mice. White mice were injected intraperitoneally with Bt. Although Bt was found in the blood at 
48 hours, it had disappeared by 72 hours. There was no vegetative growth.

c) Pathogenicity of B.t. by parenteral administration into guinea pigs. Guinea pigs injected intraperitoneally with vegetative cells of $\underline{B} . \underline{t}$. from broth culture could withstand large doses.

d) Inhalation toxicity of B.t. in mice. Mice exposed $4 \mathrm{x}$ to gram quantities of Thuricide ${ }^{R}$ while confined in a $30 \mathrm{~cm}$ square chamber showed no symptoms or change in feeding or weight. Gross pathological examinations were negative.

e) Allergenicity of Thuricide in guinea pigs. Sensitizing doses of Thuricide ${ }^{R}$ were given to guinea pigs by intracutaneous injection, the abrasion-patch technique, and by topical application on intact skin. Local irritation was found in injected and abraded animals as demonstrated by a slight erythema. No effect was observed from challenging doses given two weeks after the last sensitizing treatment. Topical applications had no effect.

f) Acute oral toxicity of Thuricide. Suspensions (33\%) of Thuricide" were placed directly into the stomachs of rats (up to $24 \mathrm{~g}$ of product ( $2 \times 10^{12}$ spores/kg body wt)). After a week, there were no deaths or symptoms of toxicity. Gross pathological examinations were also negative.

other studies involving acute and chronic feeding tests show that no toxicity was apparent in young swine, hogs, chicks, laying hens and fish are cited by Heimpel (1971). Forsberg (1976) provides a table on pp. 56-66 outlining toxicology tests to mammals, birds and fish (Appendix 3), as does Ignoffo (1973, p. 152). Ghassemi et al. 
(1981) provide a tabular summary on laboratory studies of toxicity of Btk to fish, birds and mammals (Appendix 4). Nishiitsutsuji-Uwo et al. (1980) reported that mammalian cells showed no morphological changes even at the ultra structure level when exposed to Btk. Som et al. (1986) report that Btk can not flourish in the gastrointestinal tract of guinea pigs.

According to the wHO (1981), in addition to the aforementioned tests, i.e. oral, intraperitoneal, respiratory, dermal and allergenicity and hypersensitivity, the recommended safety tests that have to be passed by bacterial pest control agents also include eye exposure (with rabbits) and mutagenicity tests (in vitro). Bacillus thuringiensis has passed these as well, in addition to a subcutaneous and 3-week feeding study. Rogoff (1982) provides a history of regulatory safety data required for Bt to satisfy the needs of the EPA. Siegel et al. (1987) provide a summary of mammalian toxicity data for the closely related variety, Bti. They conclude that Bti is not a virulent invasive mammalian pathogen, and that it can be used safely in environments where human exposure is likely to occur.

Studies by Buckner et al. (1974) on plots treated with Bt in Algonquin Park, ontario and spruce Woods, Manitoba indicated that small mammals continued breeding through the treatment periods, and trapping data indicated that the application of Bt treatments with or without chitinase did not harm the small mammal complex inhabiting treatment areas. Mammals included in the study were woodland jumping mice (Napaeozapus insignis), deer mice (Peromyscus 
maniculatus), short-tailed shrews (Blarina brevicauda), common shrews (Sorex cinereus), red-backed voles (clethrionomys gapperi), and eastern chipmunks (Tamias striatus).

In addition, proprietary data exists with Pesticides Directorate, ottawa, on acute toxicities of various formulations. 


\subsection{LITERATURE CITED}

Akiba, Y. 1986. Microbial ecology of Bacillus thuringiensis. VI. Germination of Bacillus thuringiensis spores in the soil. Appl. Entomol. 20ol. 21: 76-80.

Akiba, Y., Y. Sekijima, K. Aizawa and N. Fujiyoshi. 1977. Microbial ecological studies on Bacillus thuringiensis II. Dynamics of Bacillus thuringiensis in sterilized soil. Jap. J. App. Entomol. 2001. 21: 41-46.

Atkins, E.L. et al. 1975. Toxicity of pesticides and other agricultural chemicals to honeybees- Laboratory studies. University of California. Dev. Agric. Sci. Leaflet 2287.

Bailey, L. 1971. The safety of pest-insect pathogens for beneficial insects. In: Microbial control of insects and mites. H.D. Burges and N.W. Hussey, eds. Academic Press, New York. pp. 491-505.

Beckwith, R.C. and M.J. Stelzer. 1987. Persistence of Bacillus thuringiensis in two formulations applied by helicopter against the western spruce budworm (Lepidoptera: Tortricidae) in north central oregon. J. Econ. Entomol. 80: 204-207.

Beegle, C.C., T.L. Couch, R.T. Alls, P.L. Versoi and B.L. Lee. 1986. Standardization of HD-1-S-1980: U.S. standard for assay of lepidopterous-active Bacillus thuringiensis. Bull. Entomol. Soc. Amer. $32: 44-45$.

Beegle, C.C, H.T. Dulmage, D.A. Wolfenbarger and E. Martinez. 1981. Persistence of Bacillus thuringiensis Berliner insecticidal activity on cotton foliage. J. Environ. Entomol. 10: 400-401.

Benz, G. and A. Altwegg. 1975. Safety of Bacillus thuringiensis for earthworms. J. Invert. Pathol. 26: 125-126.

Benz, G. and K. Boursiewiez. 1963. A method for the differential staining of spores and parasporal bodies of Bacillus thuringiensis Berliner and Bacillus fribocergensis. J. Insect Pathol. 5: 393-94.

Bryant, J.E. and W.G. Yendol. 1988. Evaluation of the influence of droplet size and density of Bacillus thuringiensis against Gypsy moth larvae (Lepidoptera: Lymantriidae). J. Econ. Entomol. 81: 130134 .

Buckner, C.H., P.D. Kingsbury, B.B. McLeod, K.L. Mortensen and D.G.H. Ray. 1974. Evaluation of commercial preparations of Bacillus thuringiensis with and without chitinase against spruce budworm. F. Impact of aerial treatment on non-target organisms. Chem. cont. Res. Inst. Info. Rep. CC-X-59.

Burgerjon, A. and D. Martouret. 1971. Determination and 
significance of the host spectrum of Bacillus thuringiensis. In: Microbial Control of Insects and Mites. H.D. Burges and N.W. Hussey, eds. Academic Press, New York. pp. 305-322.

Burges, H.D. 1981. Safety, safety testing and quality control of microbial pesticides. In: Microbial control of Pests and Plant Diseases 1970-1980. H.D. Burges, ed. Academic Press, New York. pp. $737-767$.

Burges et al. 1966. The standardization of Bacillus thuringiensis tests on three candidate reference materials. In: Insect pathology and microbial control. P.A. van der Laan, ed. North-Holland, Amsterdam. pp. 314-338.

Burges, H.D., E.M. Thompson and R.A. Latchford. 1976. Importance of spores and endotoxin protein crystals of Bacillus thuringiensis in Galleria mellonella. J. Invert. Pathol. 27: 87-94.

Cabana, J. and M. Pelletier. 1986. Surveillance des pulverisations aeriennes d'insecticides contre la tordeuse des bourgeons de l'epinette au Quebec, en 1985. Controle de la qualite effectue, en 1985, sur les preparations a base de Bacillus thuringiensis. I. Recherche de pathogenes et identification de l'espece insecticide. Ministere de l'Energie et des Resources, Quebec.

Cadogan, B.L., B.F. Zylstra, C. Nystrom, P.M. Ebling and L.B. Pollock. 1986. Evaluation of a new Futura formulation of Bacillus thuringiensis on populations of jackpine budworm, Choristoneura pinus pinus (Lepidoptera: Tortricidae). Proc. Entomol. Soc. Ont. 117: $59-64$.

Carrow, J.R., S.A. Nicholson and R.A. Campbell. 1981. Aerial spraying for forest management- an operational manual. Ont. Min. Nat. Res. 44 pp.

de Barjac, H. 1981. Identification of H-serotypes of Bacillus thuringiensis. In: Microbial control of pests and plant diseases. H.D. Burges, ed. Academic Press, New York. pp. 36-43.

Delucca. A.J. II, M.S. Palmgren and A. Ciegler. 1982. Bacillus thuringiensis in grain elevator dusts. Can. J. Microbiol. 28: 45256 .

Delucca, A.J. II, J.G. Simonson and A.D. Larson. 1981. Bacillus thuringiensis distribution in soils of the United States. Can. J. Microbiol. 27: 865-70.

Dimond, J.B. and C.J. Spies III. 1981. Two-year effects of a Bacillus thuringiensis treatment on spruce budworm, Choristoneura fumiferana (Lepidoptera: Tortricidae). Can. Entomol. 113: 661-663. 
Dubois, N.R. and F.B. Lewis. 1981. What is Bacillus thuringiensis? J. Arboriculture 7: 233-240.

Dulmage, H.T. 1973. Bacillus thuringiensis U.S. assay standard. Report on the adoption of a primary U.S. reference standard for assay of formulations containing the delta-endotoxin of Bacillus thuringiensis. Bull. Entomol. Soc. Amer. 19:200-202.

Dulmage, H.T. and K. Aizawa. 1982. Distribution of Bacillus thuringiensis in nature. In: Microbial and viral pesticides. E. Kurstak, ed. Marcel Dekker Inc. New York. pp. 209-237.

Dulmage, H.T. and Cooperators. 1981. Insecticidal activity of isolates of Bacillus thuringiensis and their potential for pest control. In: Microbial control of pests and plant diseases 19701980. H.D. Burges, ed. Academic Press, New York. pp. 193-222.

Dunbar, J.P. and A.W. Johnson. 1975. Bacillus thuringiensis: effects on the survival of a tobacco budworm parasitoid and predator in the laboratory. Environ. Entomol. 4: 352-354.

Eidt, D.C. 1985. Toxicity of Bacillus thuringiensis var. kurstaki to aquatic insects. Can. Entomol. 117: 829-837.

Falcon, L.A. 1971. Use of bacteria for microbial control of insects. In: Microbial control of insects and mites. H.D. Burges and N.W. Hussey, eds. Academic Press, New York. pp. 67-95.

Fast, P.G. 1981. The crystal toxin of Bacillus thuringiensis. In: Microbial control of pests and plant diseases 1970-80. H.D. Burges, ed. Academic Press, New York. pp. 223-248.

Fast, P.G. 1977. Bacillus thuringiensis delta endotoxin, on the relative roles of spores and crystals in toxicity to spruce budworm (Lepidoptera: Tortricidae). Can. Entomol. 109: 1515-18.

Fast, P.G. 1976. Some calculations relevant to field applications of Bacillus thuringiensis. Bi-monthly Research Notes 32:21. Insect Pathology Research Institute. Sault Ste. Marie, ontario, Canada.

Fast, P.G. and J. Regniere. 1984. Effect of exposure time to Bacillus thuringiensis on mortality and recovery of the spruce budworm (Lepidoptera: Tortricidae). Can. Entomol. 116: 123-160.

Faust, R.M. and L.A. Bulla Jr. 1982. Bacteria and their toxins as insecticides. In: Microbial and viral pesticides. E. Kurstak, ed. Marcel Dekker Inc. New York. pp. 75-209.

Fisher, R. and I. Rosner. 1959. Toxicology of the microbial insecticide thuricide. J. Agric. Food Chem. 7: 686-688. 
Forsberg, C.W. 1976. Bacillus thuringiensis: its effects on environmental quality. Natl. Res. Coun. Can. Public No. NRCC 15385. $134 \mathrm{pp}$.

Fortin, C., D. Lapointe and G. Charpentier. 1986. Susceptibility of brook trout (Salvelinus fontinalis) fry to a liquid formulation of Bacillus thuringiensis serovar. israelensis (Teknar ${ }^{R}$ used for blackfly control. Can. J. Fish. Aquat. Sci. 43: 1667-1670.

Ghassemi, M. , L. Fargo, P. Painter, P. Painter, S. Quinlivan, R. Scofield, A. Takata. 1981. Environmental fates and impacts of major forest use pesticides. EPA Contract No. 68-02-3174.

Gingric, R.E., N. Allen and D.E. Hopkins. 1974. Bacillus thuringiensis: Laboratory tests against four species of biting lice (Mallophaga: Trichodectidae). J. Invert. Pathol. 23: 232-36.

Hassan, S.A., F. Bigler, H. Bogenschutz, J.U. Brown, S.I. Firth, P. Huang, M.S. Ledieu, E. Naton, P.A. Oomen, W.P.J. Overmeer, W. Rieckmann, L. Samsoe-Petersen, G. Viggiani, A.Q. van Zon. 1983. Results of the second joint pesticide testing programme by the IOBC/WPRS-working group "pesticides and beneficial arthropods." Zeitschrift fur Angewandte Entomologie 95:151-158.

Haverty, M.I. 1982. Sensitivity of selected non-target insects to the carrier of Dipel $4 \mathrm{~L}$ in the laboratory. Environ. Entomol. 11: 337-338.

Heimpel, A.M. 1971. Safety of insect pathogens for man and vertebrates. In: Microbial control of insects and mites. H.D. Burges and N.W. Hussey, eds. Academic Press, New York. pp. 469-489.

Heimpel, A.M. 1967. A critical review of Bacillus thuringiensis var. thuringiensis Berliner and other crystalliferous bacteria. Annu. Rev. Entomol. 12: 287-322.

Ignoffo, C.M. 1973. Effects of entomopathogens on vertebrates. In: Regulation of insect populations by microorganisms. L.A. Bulla Jr. Ed. Ann. N.Y. Acad. Sci. 217. pp. 141-172.

Ignoffo, C.M. and C. Garcia. 1978. UV-photoinactivation of cells and spores of Bacillus thuringiensis and effects of peroxidase on inactivation. Environ. Entomol. 7: 270-2.

Jaquet, F., R. Hutter and P. Luthy. 1987. Specificity of Bacillus thuringiensis delta endotoxin. Appl. Env. Microbiol. 53: 500-4.

Krieg, A. 1975. Photoprotection against inactivation of Bacillus thuringiensis spores by ultraviolet rays. J. Invert. Pathol. 25: $267-268$.

Krieg, A. 1971. Concerning exotoxin produced by vegetative cells 
of Bacillus thuringiensis and Bacillus cereus. J. Invert. Pathol. 17: 134-135.

Krieg, A. and G.A. Langenbruch. 1981. Susceptibility of arthropod species to Bacillus thuringiensis In: Microbial control of pests and plant diseases 1970-1980. H.D. Burges, ed. Academic Press, New York. pp. 837-896.

Leong, K.L.H., R.J. Cano and M. Kubinski. 1980. Factors affecting Bacillus thuringiensis total field persistence. Environ. Entomol. 9: 593-99.

Luthy, P., J.L. Cordier and H.M. Fischer. 1982. Bacillus thuringiensis as a bacterial insecticide: Basic considerations and application. In: Microbial and viral pesticides. E. Kurstak, ed. Marcel Dekker Inc., New York. pp. 35-74.

Mcleod, P.J., W.C. Yearian and S.Y. Young. 1983. Persistence of Bacillus thuringiensis on second year lobolly pine cones. Environ. Entomol. 12: 1190-92.

Menon, A.S. and J. de Mestral. 1985. Survival of Bacillus thuringiensis var. kurstaki in waters. Water, Air and Soil Poll. 25: 265-74.

Morris, O.N. 1983. Comparative efficacy of Thuricide 16B and Dipel 88 against the spruce budworm, Choristoneura fumiferana (Lepidoptera: Tortricidae) in balsam fir stands. Can. Entomol. 115: 1001-1006.

Morris, O.N. 1982. Bacteria as pesticides: Forest application. In: Microbial and viral pesticides. E. Kurstak, ed. Marcel Dekker Inc. N. Y. pp. 239-287.

Morris, O.N. 1977. Long term study of the effectiveness of Bacillus thuringiensis-acephate combinations against spruce budworm Choristoneura fumiferana (Lepidoptera: Tortricidae). Can. Entomol. 109: 1239-48.

Morris, O.N. and M.J. Hildebrand. 1974. Evaluation of commercial preparations of Bacillus thuringiensis with and without chitinase against spruce budworm., E. Assessment of effectiveness of aerial application, Algonquin Park, ontario. Can. For. Ser. Inf. Rpt. CC$\mathrm{X}-59$. p. E14.

Nishiitsutsuji-Uwo, J., Y. Endo and M. Himeno. 1980. Effects of Bacillus thuringiensis delta endotoxin on insect and mammalian cells in vitro. Appl. Entomol. Zool. 15: 133-139.

Niwa, C.G., M.J. Stelzer, R.C. Beckwith. 1987. Effects of Bacillus thuringiensis on parasites of western spruce budworm (Lepidoptera: Tortricidae). J. Econ. Entomol. 80: 750-753. 
Ohba, M. and K. Aizawa. 1986. Distribution of Bacillus thuringiensis in soils of Japan. J. Invert. Pathol. 47: 277-282.

OMAF (Ontario Ministry of Agriculture and Food). 1988. Vegetable production recommendations. Public. 363. $78 \mathrm{pp}$.

orton, D. 1987. The case against forest spraying with the bacterial insecticide Bt. Alternatives 15: 28-35.

Petras, S.F. and L.E. Casida Jr. 1985. Survival of Bacillus thuringiensis spores in soil. Appl. Environ. Microbiol. 50: 14961501 .

Poirier, D.G. and G.A. Surgeoner. 1988. Evaluation of a field bioassay technique to predict the impact of aerial applications of forestry insecticides on stream invertebrates. Can. Entomol. 120: $627-37$.

Pruett, C.J.H., H.D. Burges and C.H. Wyborn. 1980. Effect of exposure to soil on potency and spore viability of Bacillus thuringiensis. J. Invert. Pathol. 35: 168-174.

Reardon, R.C. and K. Haissig. 1984. Efficacy and persistence of Bacillus thuringiensis after ground application to balsam fir and white spruce in Wisconsin. Can. Entomol. 116: 153-158.

Retnakaran, A., H. Lauzon and P. Fast. 1983. Bacillus thuringiensis induced anorexia in the spruce budworm, Choristoneura fumiferana. Entomol. Expt. Appl. 34: 233-239.

Rogoff, M.H. 1982. Regulatory safety data requirements for registration of microbial pesticides. In: Microbial and viral pesticides. E. Kurstak, ed. Marcel Dekker Inc., New York. pp. 645679 .

Salama, H.S., M. Foda and M. Selim. 1984. Isolation of B. thuringiensis mutants resistant to physical and chemical factors. Z. Ang. Entomol. 97: 139-145.

Saleh, S.M., R.F. Harris and O.N. Allen. 1970. Fate of Bacillus thuringiensis in soil. Effect of soil pH and organic amendment. Can. J. Microbiol. 16: 677-80.

Samples, J.R. and H. Buettner. 1983. Corneal ulcer caused by a biologic insecticide (Bacillus thuringiensis). Am. J. Opthalmol. 95: $258-60$.

Sebesta, K., J. Farkas and K. Horska. 1981. Thuringiensin, the beta exotoxin of Bacillus thuringiensis. In: Microbial control of pests and plant diseases 1970-1980. H.D. Burges, ed. Academic Press, New York. pp. 249-281. 
Siegel, J.P., J.A. Shadduck and J. Szabo. 1987. Safety of the entomopathogen Bacillus thuringiensis var. israelensis for mammals. J. Econ. Entomol. 80: 717-723.

sitting, M. 1980. Pesticide manufacturing and toxic materials control encyclopedia. Park Ridge, New Jersey. 810 pp.

Smirnoff, W.A. and C.F. Mcleod. 1961. Study of the survival of Bacillus thuringiensis var. thuringiensis Berliner in the digestive tracts and in feces of a small mammal and birds. J. Insect pathol. $3: 266-270$.

Smith, R.A. and J.T. Ulrich. 1983. Enzyme-linked immunosorbent assay for quantitative detection of Bacillus thuringiensis crystal protein. Appl. Environ. Microbiol. 45: 586-90.

Som, N.C., B.B.G. Hosh and M.K. Majumdar. 1986. Effects of Bacillus thuringiensis and insect pathogen, Pseudomonas aeruginosa, on mammalian gastrointestinal tract. Ind. J. Exp. Biol. 24: 102-107.

Steinhaus, E.A. 1959. on the improbability of Bacillus thuringiensis Berliner mutating to forms pathogenic to vertebrates. J. Econ. Entomol. 52: 506-8.

Szuba, K.J., B.J. Naylor and J.F. Bendell. 1988. Indirect effects of a bacterial insecticide (…․) on wild spruce grouse chicks. Unpublished manuscript in preparation.

Ticehurst, M., R.A. Fusco and E.M. Blumenthal. 1982. Effects of reduced rates of Dipel 4L, Dylox 1.5 Oil and Dimilin $W-25$ on Lymantria dispar (L.) (Lepidoptera: Lymantriidae) parasitism, and defoliation. Environ. Entomol. 11: 1058-62.

Tipping, P.W. and P.P. Burbutis. 1983. Some effects of pesticide residues on Trichogramma nubilae (Hymenoptera: Trichogrammatidae). J. Econ. Entomol. 76: 892-896.

Todd, I.S. and K.J. Jackson. 1961. The effects on salmon of a program of forest insect control with DDT on Northern Moresby Island. Can. Fish. Cult. 30: 15-38.

Warren, R.E., D. Rubenstein, D.J. Ellar, J.M. Kramer and R.J. Gilbert. 1984. Bacillus thuringiensis var. israelensis protoxin activation and safety. The Lancet, March 1984: 678-679.

West, A.A., N.E. Crook and H.D. Burges. 1984. Detection of Bacillus thuringiensis in soil by immunofluorescence. J. Invert Pathol. 43: $150-155$.

WHO (World Health organization). 1981. Mammalian safety of microbial agents for vector control: A WHO memorandum. Bull. WHO 59: $857-863$. 
Wie, S.I., R.E. Andrews, B.D. Hammock, R.M. Faust and L.A. Bulla. 1981. Enzyme linked immunosorbent assays for detection and quantification of the entomocidal parasporal crystalline protein of Bacillus thuringiensis subspp. kurstaki and israelensis. Appl. Environ. Microbiol. 43: 891-4.

Wilkinson, J.D., K.D. Biever and C.M. Ignoffo. 1975. Contact toxicity of some chemical and biological pesticides to several insect parasitoids and predators. Entomophaga 20: 113-120. 
Appendix 1 .

Acrriculture

Cancatas

Focotprodis tion and

Pesticilies Directorate

Direction geriserilte.

ottawa, Ontario

KIA 0 C6

February 22,1988

MEMORANDUM TO: Bt Manufacturers

Federal and Provincial Forestry Authorities

Federal and Provincial Health Authorities

Federal and Provincial Environment Authorities

Re: Bacillus thuringiensis (B.t.)

Over the last number of years, there has been a continual increase in the use and acceptance of $B . t$. for various control programs. Against this background, we have been encouraged to develop quality assurance guidelines for the presence of extraneous microorganisms. We are endeavouring to develop in cooperation with Health and Welfare Canada colleagues, industry and provincial governments, a product profile which will characterize B.t. formulations.

This program represents a new regulatory initiative not previously undertaken for B.t., or any other microbial product. At the present time, standards have not been established in the Pest Control Products Regulations. Thus, our current efforts should be viewed as an administrative guideline which will serve as an interim reference and, hopefully, lead to the establishment of more definitive, formal standards in the future.

It is recognized that there is a degree of variability inherent in large scale manufacturing operations, even within the same plant. Therefore, some baseline or hands on experience in typical product profiles is essential to establish a practical regulatory standard. Based on experiences in 1987 and subsequent wide ranging discussions, interim "target values" as outlined in the attached document have been developed. These initial parameters reflect background information on quality standards in other areas and an assessment of currently available manufacturing technology taking into consideration the projected 1988 provincial forestry program demands. 
a) Sampling: $125 \mathrm{ml}$ screw top, plastic containers as well as detailea instructions re: sampling, packing and shipping procedures will be provided by Ag Canada's Laboratory Services to Regional staff and to provincial authorities.

Samples: Bulk Shipment: $1(x 2)$ * sample/tanker compartment Barrels : NO. OF SAMPLES / LOT SIZE

$\begin{array}{rrll}4 & (\times 2) * & / & 1-30 \text { barrals } \\ 6 & " & / & 31-60 \\ 8 & " & / & 61-90 \\ 10 & " & / & 91-120 "\end{array}$

* In order maintain a reference sample and for the sake of precaution re: handling, duplicate samples will be taken for each compartment/barrel as indicated above.

Laboratory Methodology:

Salmonella:

Streptococci/Enterococci :

Coliforms :

Clostridium perfringens:

Staphylococcus aureus:

Pseudomonas aeruginosa:
- $M F-H P B-20$

- m-Enterococcus Agar

- Pour Plate or HGMF

- Violet Red Bile Glucose (VRBG) Agar

- Pour Plate or Hydrophobic Grid Membrane Filtration (HGMF) Method

- MF-HPB-23: Methods Food - Health Protection Branch - 23

- Pour Plate of HGMF Method

- MF-HPB-- 21

- m-PA-C Agar

- HGMF Method

In order to ensure compatability of results, Agriculture Canada will provide the BT companies and provincial agencies with the detailed laboratory methodology for each of the selected microorganisms.

W. E. Stewart, Ph.D.

Product Management

Pesticides Directorate

$2087 E$ 
In the early summer of $198 \%$. concerns were raised regarding the presence of microcontaminants (specifically fecal streptococcus). found in formulations of BT. In response to the concerns. Agriculture Canada carried out an extensive sampling program of representative batches of BT that were being used in the major forestry operations across canada. These samples were analysed for fecal streptococci by our Laboratory services and results compared to those carried out by several provinces and by one of the Health \& Welfare Canada laboratories. Discussions regarding the significance of the levels of streptococcus indicated that these organisms are common in many non-sterile foods and in the natural environment, represented either non-or low-order pathogenicity and that exposure under typical forestry use applications would not likely produce adverse health effects.

Additional questions have since been raised by some of the forestry community regarding the possibility of additional microcontaminants being present and whether Canadian standards (for BT) should be established.

While no specific standards have ever been set for BT manufacturing. there has always been the Internationally accepted understanding/guarantee by companies that BT products would contain no exotoxin and would be free of the human/animal pathogens salmonela/shigella and Vibrio. At present however. the 7 day mouse test (measuring presence/absence of exotoxin) appears to be the only test carried out regulary by most companies.

In order to address the questions raised by last summer's experiences, it was necessary to review the manufacturing process for BT with the various companies and to try to establish where in the process microcontamination could occur and how contamination might be controlled and prevented. Therefore, an informal, multi-department comittee was established consisting of members from: Ag Can: Laboratory Services. Pesticides Directorate: Canadian Forestry Service: H\&W: Bureau of Microbial Hazzards. Environmental Health Directorate. Foods Directorate. Laboratory Centre for Disease Control). 
Early discussions centered on the historical aspects of the use of BT (especially in Forestry). the formulations presently available, and on the events of last summer. The following meetings were organized and held with the major BT

companies: -October 27. 1987 - Abbott Laboratories. -November 26. 1987 - Duphar/ChemAgro Ltd. - December 7. 1987 - Sandoz Inc.

Companies were asked to present their BT manufacturing and formulating processes, their quality control process, and information on storage stability. The topic of microcontamination was discussed in terms of what extraneoùs (bio) contaminants companies tested for: - routinely. -in 1987: what stages of the manufacturing process the microcontaminants could occur: and what steps the companies were taking to control microcontamination. The possibility and practicality of testing for microcontamination using indicator organisms similar to those used in food manufacturing was discussed.

Summary:

All BT is manufactured using the classical fermentation process.

Neither the fermentation equipment nor the raw materials are considered to be potential sources of contamination since the fermentation equipment is mainly stainless steel and is thoroughly cleaned between batches and the raw material components and additives of the manufacturing process are typically of high quality.

Manufacturing process may be divided into two stages:

a) production of the technical or most concentrated form - either a thick pasty concentrate or a dry primary powder.

b) production of the formulated/end use products which are derived from the concentrate or primary powder.

Much of the process for producing the technical material is carried out under aseptic conditions, however, at certain stages of the process, e.g. centrifugation, it is not possible to prevent exposure of the material to air and hence possible contamination. 
The production of the final end use (formulated) product(s) occurs under non sterile conditions and as potential for exposure and therefore presents opportunity for contamination to occur.

When BT is packaged and shipped in barrels only new containers are used. therefore, it is unlikely that significant contamination would result from packaging.

For bulk shipments of BT (up to 20.000 or more 1 itres). bulk tankers are normally steam cleaned but may in fact present an opportunity for contamination.

Conclusions:

On the part of the manufacturer, the most likely potential for contamination would be:

a) during concentration of the technical material

b) during production of final end use (formulated) products

c) from bulk shippment equipment.

Once the formulated product(s) is delivered. the opportunity for the introduction of microcontaminants may result from:
a) the user's storage tanks/facilities
b) mixing procedures/eguipment
c) handing of formulated product.

W.E. Stewart, Ph.D.

Product Management

Pesticides Directorate

WES/Sn

$2001 \mathrm{E}$ 
Based on the limited experience available to date, and the advice emerging from government/industry consultation, we would expect all supplies to fall within the proposed target values. Indeed, typical properties of any particular production lot are expected to be below these figures.

It is reasonable to assume process and quality assurance techniques can markedly influence contaminant levels. These features may vary among manufacturers. Agencies interested in establishing more restrictive quality assurance parameters may wish to discuss this element with potential suppliers and define their specific requirements in tender proposals.

In responding to representations for quality assurance parameters on B.t., we have attempted to reflect a reasonable and practical regulatory approach. We have endeavoured to take into consideration safeguards regarding human health as well as practical realities that exist. It is hoped that this approach will accommodate the needs of all parties involved and encourage industry to upgrade product quality.

W. E. Stewart

Insecticide Evaluation Officer Product Management Division

Swo/sn

(1.78)0098e 


\section{I. PROPOSED MONITORING $3 Y$ MANUFACTURER}

- It is proposed that B.t. producers carry out a monitoring program of their own and provide results re: selected organism testing (as per methodology provided) on each lot of formulated product sampled at the point of delivery/ transfer.

\section{ADDITIONAL MONITORING AND RECOMMENDATIONS}

a) To further define quality assurance procedures after delivery to users, Agriculture Canada would like to gather additional monitoring information on the storage and composition of formulated B.t., e.g.:

- Report on provincial B.t. storage tanks re: their structure, condition and cleaning procedures/facilities.

- Sample and test B.t. after it has been transferred to holding tanks and/or mixed and held prior to intended use.

b) B.t. producers may wish to consider additional monitoring

for the presence of the selected microorganisms, e.g.:

- The general manufacturing environment (fermenting/formulating facilities)

- Each lot of technical powder or concentrate.

- Each lot of formulated product at the point of packaging i.e., when barrels and/or bulk containers are being filled.

- Bulk tankers, to assure that cleaning procedures e.g., steam, are carried out and are effective.

- Additional Organism(s): Companies are asked to provide Agriculture Canada with specific details of any organism(s) which may have been used as part of their Bt. manufacturing or development processes.

\section{EVALUATION OF RESULTS:}

- Laboratory results from industry, the provinces and Ag Canada will be reviewed and compared by Ag Canada and our advisors in H\&W. 
AVAILABILITY OF RESULTS:

- Consistent with our operating practices, specific test results obtained by Agriculture Canada from the 1988 monitoring program will be made available.

William E. Stewart, Ph.D.

Product Management

Pesticides Directorate 
Appendix 2. Aerial Application of Bacillus thuringiensis in Ontario by MNR, 1980-1987 (1,228,727 ha treated with 2,156,830+ Litres Btk). (Data provided by J. Churcher, OMNR).

1980-Spruce Budworm

Total Ha

Sprayed

10,310
Ha Bt

Sprayed

4,640
Product

Used

Thuricide 16B

Dipel 88

Novabac 3-e
Application

$\underline{\text { Rate }}$

$?$
$?$

Bt (L)

Used

$$
\begin{aligned}
& ? \\
& ? \\
& ?
\end{aligned}
$$

\section{0-Oak Leaf Shredder}

\begin{tabular}{|c|c|c|c|c|}
\hline $\begin{array}{l}\text { Total Ha } \\
\text { Sprayed }\end{array}$ & $\begin{array}{l}\text { Ha Bt } \\
\text { Sprayed }\end{array}$ & $\begin{array}{l}\text { Product } \\
\text { Used }\end{array}$ & $\begin{array}{l}\text { Application } \\
\text { Rate }\end{array}$ & $\begin{array}{l}\text { Bt (L) } \\
\text { Used }\end{array}$ \\
\hline 9,972 & $\begin{array}{r}296 \\
324 \\
1,099 \\
862 \\
670 \\
810 \\
846 \\
1,731 \\
\underline{262} \\
6,900\end{array}$ & $\begin{array}{l}\text { Dipel } 88 \\
\text { Thuricide } 32 \mathrm{~B} \\
\text { Dipel } 88 \\
\text { Dipel } 88 \\
\text { Thuricide } 16 \mathrm{~B} \\
\text { Thuricide } 16 \mathrm{~B} \\
\text { Dipel } 88 \\
\text { Thuricide } 16 \mathrm{~B} \\
\text { Thuricide } 16 \mathrm{~B}\end{array}$ & $\begin{array}{ll}24 & \mathrm{BIU} / 7 \mathrm{~L} / \mathrm{ha} \\
20 & \mathrm{BIU} / 4.7 \mathrm{~L} / \mathrm{ha} \\
20 & \mathrm{BIU} / 5.9 \mathrm{~L} / \mathrm{ha} \\
20 & \mathrm{BIU} / 2.4 \mathrm{~L} / \mathrm{ha} \\
20 \mathrm{BIU} / 7.2 \mathrm{~L} / \mathrm{ha} \\
20 \mathrm{BIU} / 7 \mathrm{~L} / \mathrm{ha} \\
20 \mathrm{BIU} / 5.1 \mathrm{~L} / \mathrm{ha} \\
16 \mathrm{BIU} / 6.2 \mathrm{~L} / \mathrm{ha} \\
16 \mathrm{BIU} / 6.2 \mathrm{~L} / \mathrm{ha} \\
\\
(2 \mathrm{X})\end{array}$ & $\begin{array}{r}835 \\
760 \\
2,585 \\
2,070 \\
3,190 \\
3,855 \\
1,990 \\
6,595 \\
1,995\end{array}$ \\
\hline
\end{tabular}

$\begin{array}{cllll}\begin{array}{l}\text { Total Ha } \\ \text { Sprayed }\end{array} & \begin{array}{l}\text { Ha Bt } \\ \text { Sprayed }\end{array} & \begin{array}{l}\text { Product } \\ \text { Used }\end{array} & \text { Application } & \text { Bt (L) } \\ \text { Rate } & \text { Used } \\ 848 & 0 & \text { N/A } & \text { N/A } & \text { N/A }\end{array}$

\section{1-Spruce Budworm}

\begin{tabular}{|c|c|c|c|c|}
\hline \multirow{2}{*}{$\begin{array}{l}\text { Total Ha } \\
\text { Sprayed }\end{array}$} & $\mathrm{Ha} \mathrm{Bt}$ & Product & Application & Bt (L) \\
\hline & Sprayed & Used & $\underline{\text { Rate }}$ & Used \\
\hline \multirow[t]{7}{*}{3,454} & 75 & Novabac 3-e & $20 \mathrm{BIU} / 7 \mathrm{~L} / \mathrm{ha}$ & 175 \\
\hline & 172 & Novabac 3-e & $20 \mathrm{BIU} / 5.9 \mathrm{~L} / \mathrm{ha}$ & 400 \\
\hline & 2,439 & Dipe1 88 & $20 \mathrm{BIU} / 5.9 \mathrm{~L} / \mathrm{ha}$ & 5,740 \\
\hline & 77 & Thuricide 32B & $20 \mathrm{BIU} / 5.9 \mathrm{~L} / \mathrm{ha}$ & 180 \\
\hline & 305 & Dipel 88 & $13 \mathrm{BIU} / 5.9 \mathrm{~L} / \mathrm{ha}$ & 465 \\
\hline & $\underline{25}$ & Thuricide $48 \mathrm{~B}$ & $30 \mathrm{BIU} / 2.4 \mathrm{~L} / \mathrm{ha}$ & 60 \\
\hline & $3,0 \overline{93}$ & & & \\
\hline
\end{tabular}

\section{2-Spruce Budworm}


1983-Spruce Budworm

Total Ha

Sprayed

3, 502

\section{Ha Bt \\ Sprayed \\ Product \\ Used}

Dipe1 88

Dipel 6L

Dipel 6L

Dipel 8L

Dipel $8 \mathrm{~L}$

Dipel 88

1,513

1,250

3,103

Dipe1 88

Novabac 3-e

Bactospiene

60

40

60

\section{3-0ak Leaf Shredder}

Total $\mathrm{Ha}$

Sprayed

$\begin{array}{ll}\text { Ha Bt } & \text { Product } \\ \text { Sprayed } & \text { Used }\end{array}$

579

$$
64 \text { Dipel } 88
$$

Application

$\underline{\text { Rate }}$

$40 \mathrm{BIU} / 4.7 \mathrm{~L} / \mathrm{ha}$
Bt (L)

Used

$$
\begin{array}{r}
105 \\
95 \\
140 \\
90 \\
105 \\
140 \\
3,560 \\
2,910 \\
210
\end{array}
$$

\begin{tabular}{|c|c|c|c|c|}
\hline Total Ha & $\mathrm{Ha} \mathrm{Bt}$ & Product & Application & Bt (L) \\
\hline Sprayed & Sprayed & Used & Rate & Used \\
\hline 29,370 & 24,370 & Dipe1 132 & $\begin{array}{l}20-30 \mathrm{BIU} / \\
1.6-2.4 \mathrm{~L} / \mathrm{ha}\end{array}$ & 42,215 \\
\hline & $\frac{5,000}{29,370}$ & Thuricide $48 \mathrm{LV}$ & $20 \mathrm{BIU} / 1.6 \mathrm{~L} / \mathrm{ha}$ & 7,875 \\
\hline
\end{tabular}

Bt (L)

Used

$$
300
$$

\section{4-Spruce Budworm}

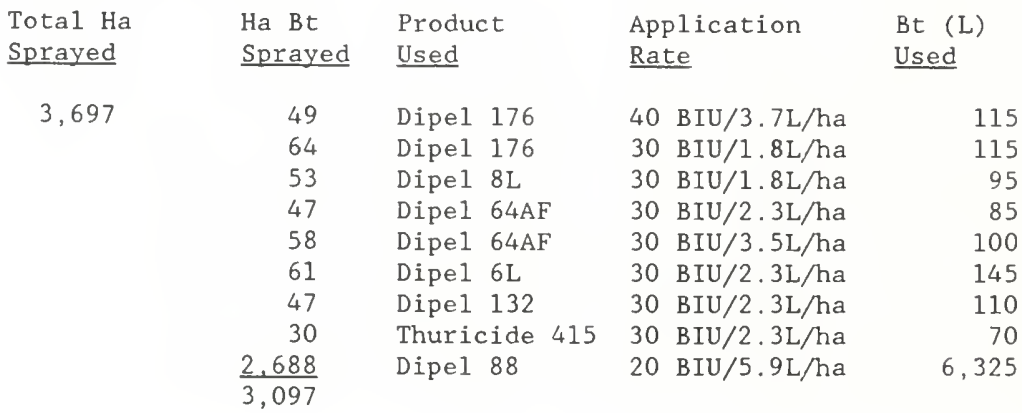

\section{5-Spruce Budworm}


Total Ha

Sprayed

220,000
$\mathrm{Ha} \mathrm{Bt}$

Sprayed

137,000

5,000

$\underline{78,000}$

220,000
Product

Used

Dipe1 132

Dipel 132

Thuricide $48 \mathrm{LV}$
Application

Rate

$20 \mathrm{BIU} / 1.6 \mathrm{~L} / \mathrm{ha}$

$20 \mathrm{BIU} / 3.2 \mathrm{~L} / \mathrm{ha}$

$20 \mathrm{BIU} / 1.6 \mathrm{~L} / \mathrm{ha}$
Bt (L)

Used

215,750

7,875

122,835

\section{5-Gypsy Moth}

Total $\mathrm{Ha}$

Sprayed

170
$\mathrm{Ha}$ Bt

Sprayed

170
Product

$\underline{\text { Used }}$

Dipel 88
Application

$\underline{\text { Rate }}$

$40 \mathrm{BIU} / 12 \mathrm{~L} / \mathrm{ha}$
Bt (L)

Used

800

\section{6-Spruce Budworm}

Total $\mathrm{Ha}$

Sprayed

150,633

Ha Bt

Sprayed

150,633
Product

Used

Dipel $132+$

Thuricide $48 \mathrm{LV}$
Application

$\underline{\text { Rate }}$

$20 \mathrm{BIU} / 1.6 \mathrm{~L} / \mathrm{ha}$

(n)

Bt (L)

Used

237,220

1986-Jack Pine Budworm

Total Ha

Sprayed

482,032
$\mathrm{Ha}$ Bt

Sprayed

482,032
Product

Used

Dipe1 $132+$

Thuricide $48 \mathrm{LV}$
Application

$\underline{\text { Rate }}$

$20 \mathrm{BIU} / 1.6 \mathrm{~L} / \mathrm{ha}$

\section{6-Gypsy Moth}

Total $\mathrm{Ha}$

Sprayed

103,094

1987-Spruce Budworm

Ha Bt
Sprayed
103,094

Product

Used

Application

$\underline{\text { Rate }}$

Dipel 132

Thuricide $48 \mathrm{LV}$

$30 \mathrm{BIU} / 6 \mathrm{~L} / \mathrm{ha}$

(2 X)
Bt (L)

Used

482,035
Total Ha

Sprayed

76,819
Ha Bt Product

Sprayed Used

76,819 Dipel 132
Application

$\underline{\text { Rate }}$

20-30 BIU/

$1.6-2.4 \mathrm{~L} / \mathrm{ha}$
Bt (L)

Used

487,060

Bt (L)

Used

151,220 
1987-Jack Pine Budworm

Total Ha

Sprayed

105,463

\section{7-Gypsy Moth}

Total Ha

Sprayed

40,249
$\mathrm{Ha}$ Bt

Sprayed

Product

Used

105,463

Dipel 132

Ha Bt Product

Sprayed Used

Application

Rate
40,249
Dipe1 $132+$
$30 \mathrm{BIU} / 6 \mathrm{~L} / \mathrm{ha}$
(2 X)

Application

Bt (L)

$\underline{\text { Rate }}$

Used

$20 \mathrm{BIU} / 1.6 \mathrm{~L} / \mathrm{ha}$

166,085
Bt (L)

Used

190,150 


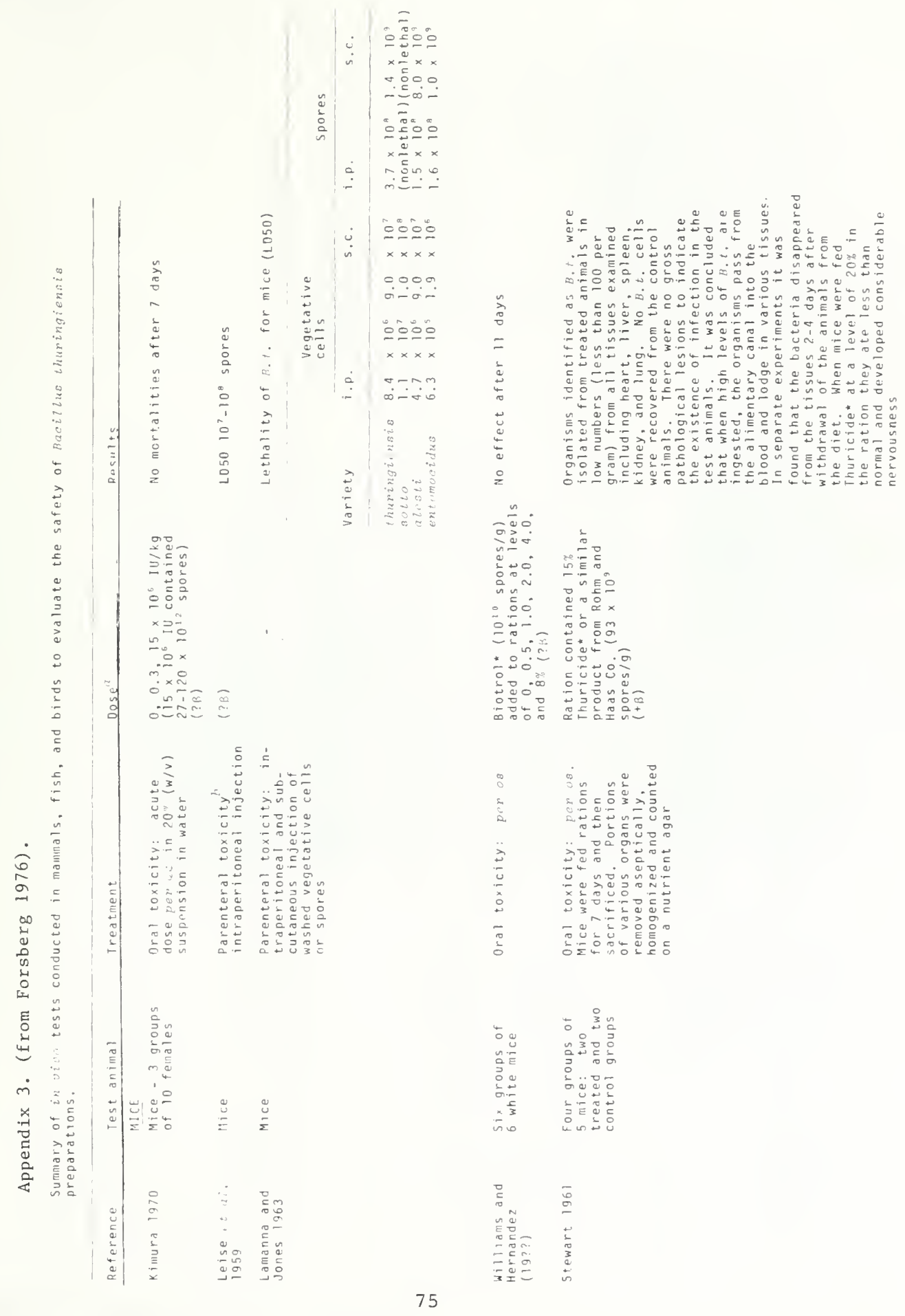




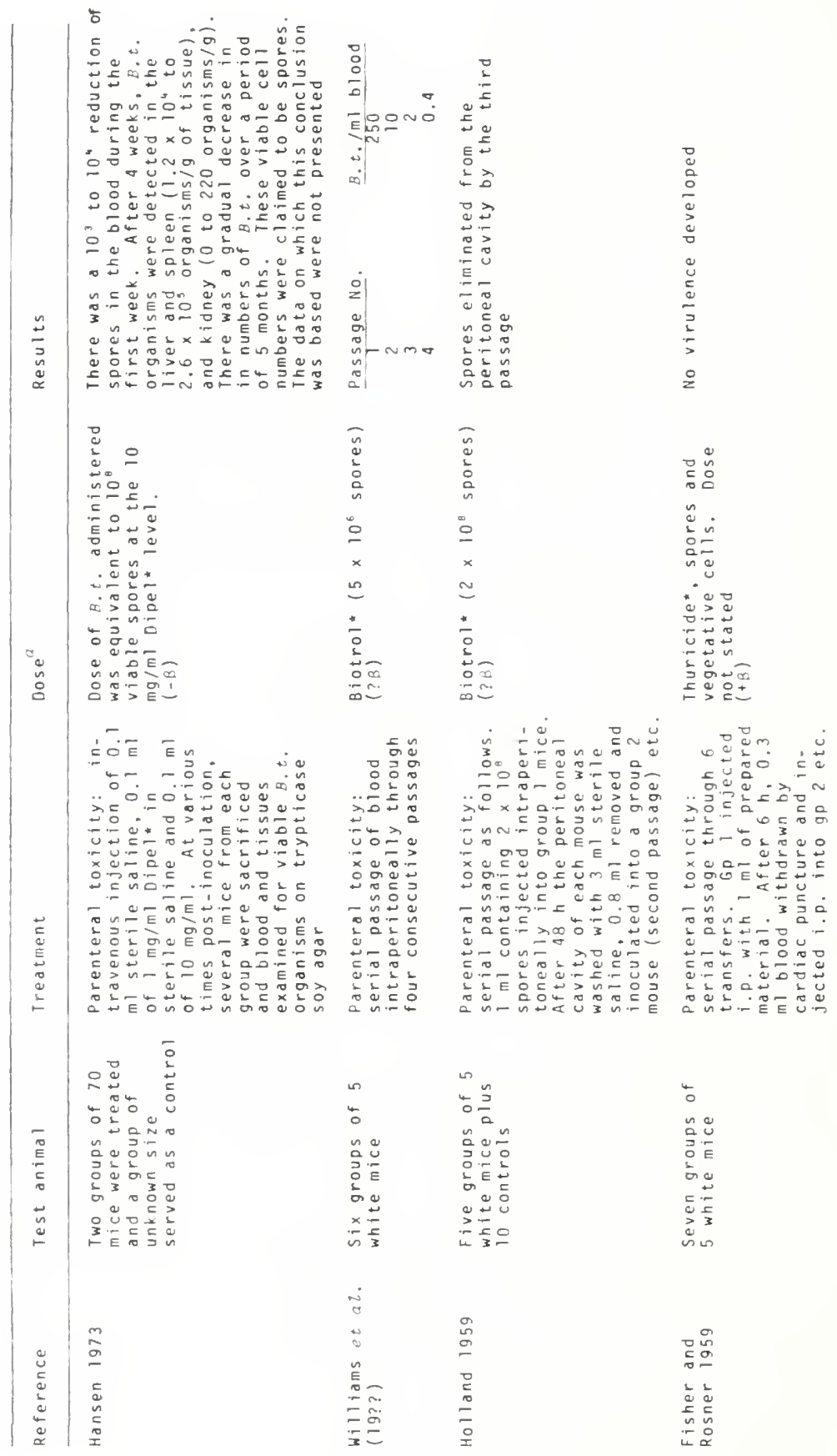




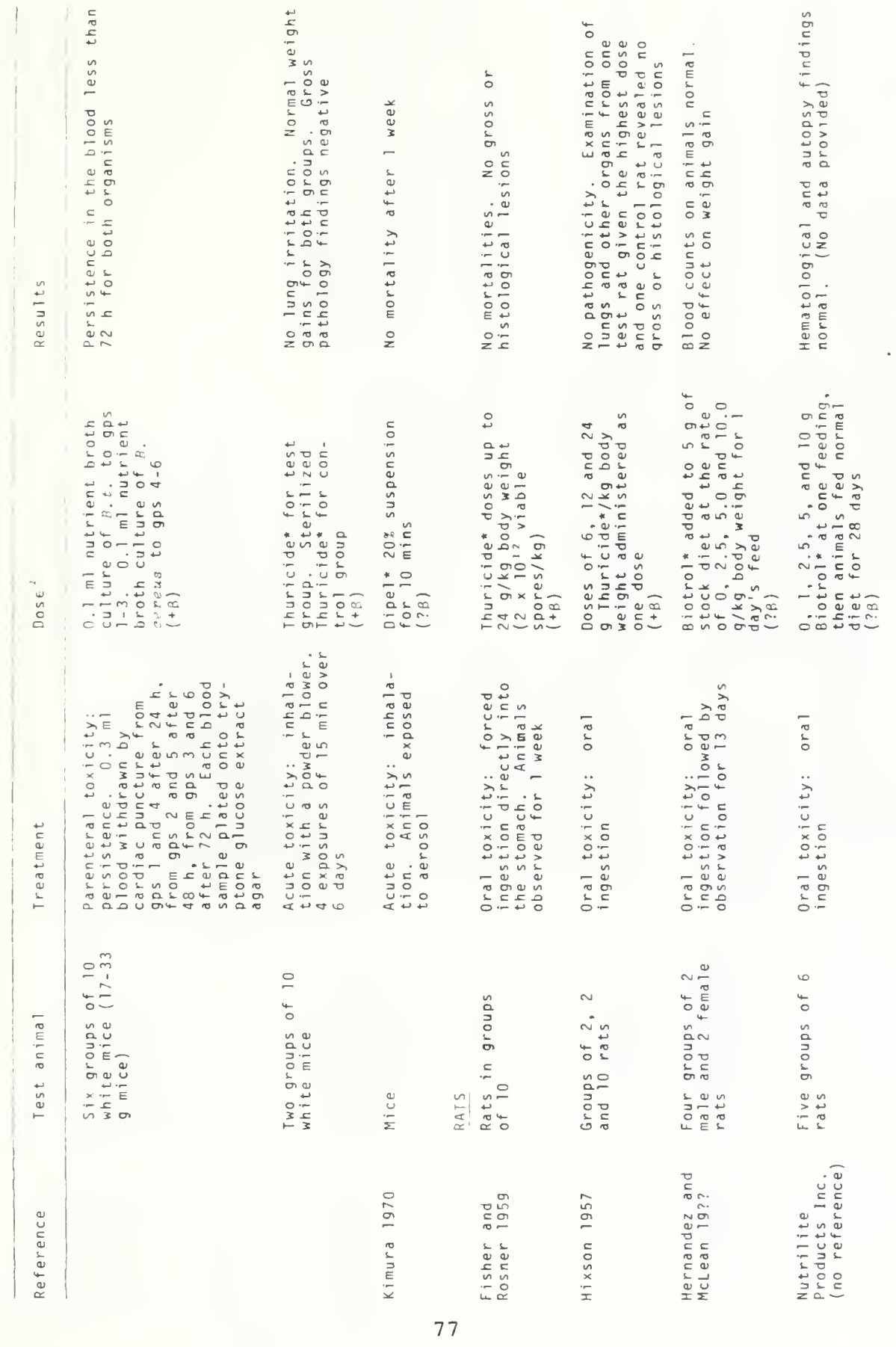




\begin{tabular}{|c|c|c|c|c|}
\hline & 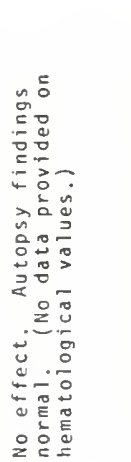 & 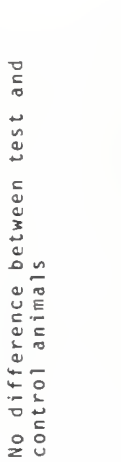 & 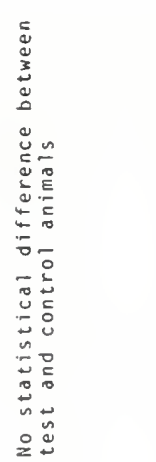 & 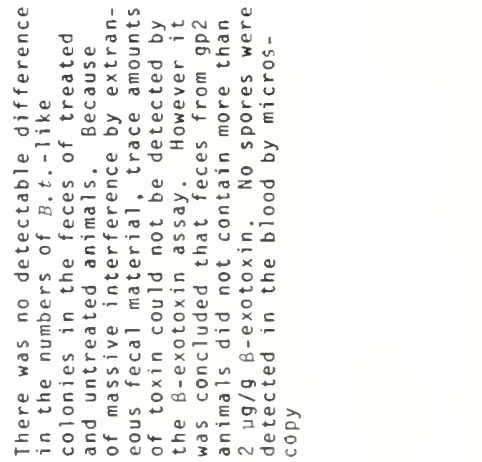 \\
\hline $\begin{array}{l}\vdots \\
\vdots \\
\therefore\end{array}$ & 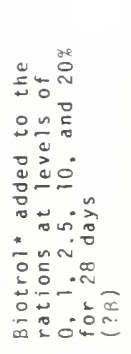 & 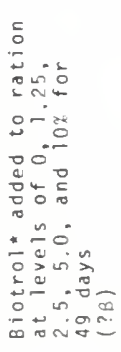 & 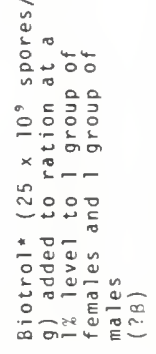 & 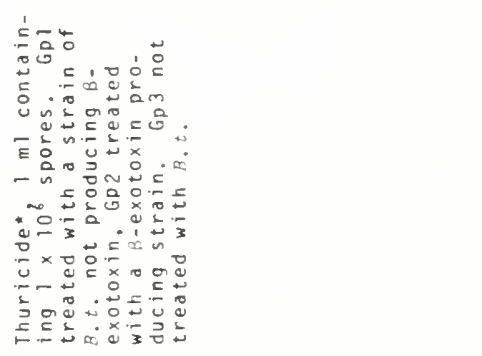 \\
\hline 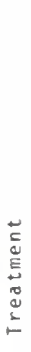 & 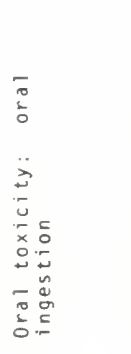 & 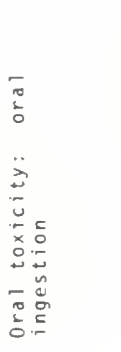 & 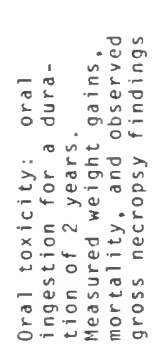 & 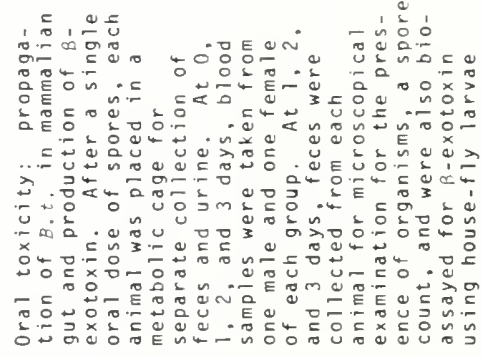 \\
\hline $\begin{array}{l}\bar{T} \\
\underline{E} \\
E \\
0\end{array}$ & $\begin{array}{l}0 \\
0 \\
0 \\
n \\
0 \\
0 \\
0 \\
0 n \\
x=0 \\
n=0\end{array}$ & 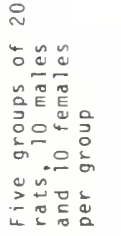 & 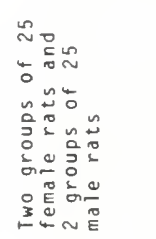 & 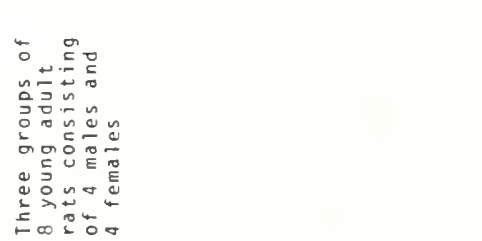 \\
\hline 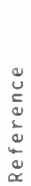 & 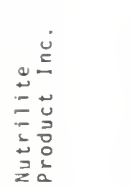 & 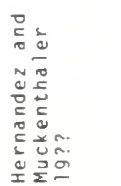 & 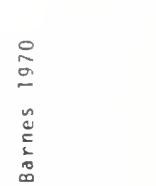 & 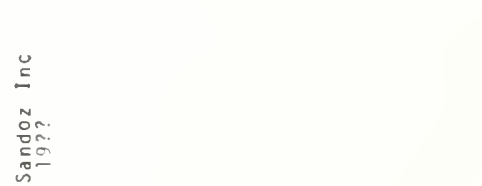 \\
\hline
\end{tabular}




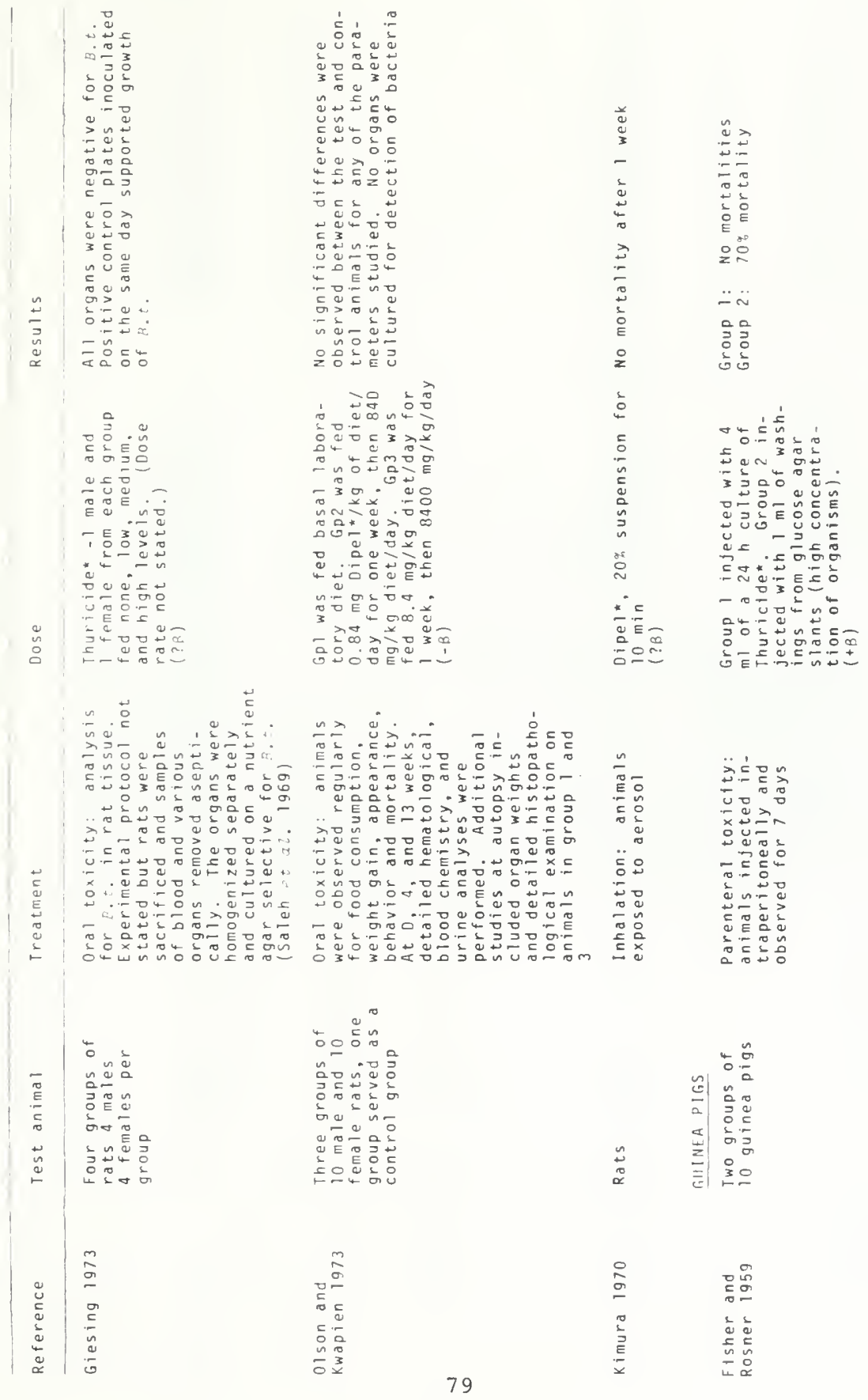




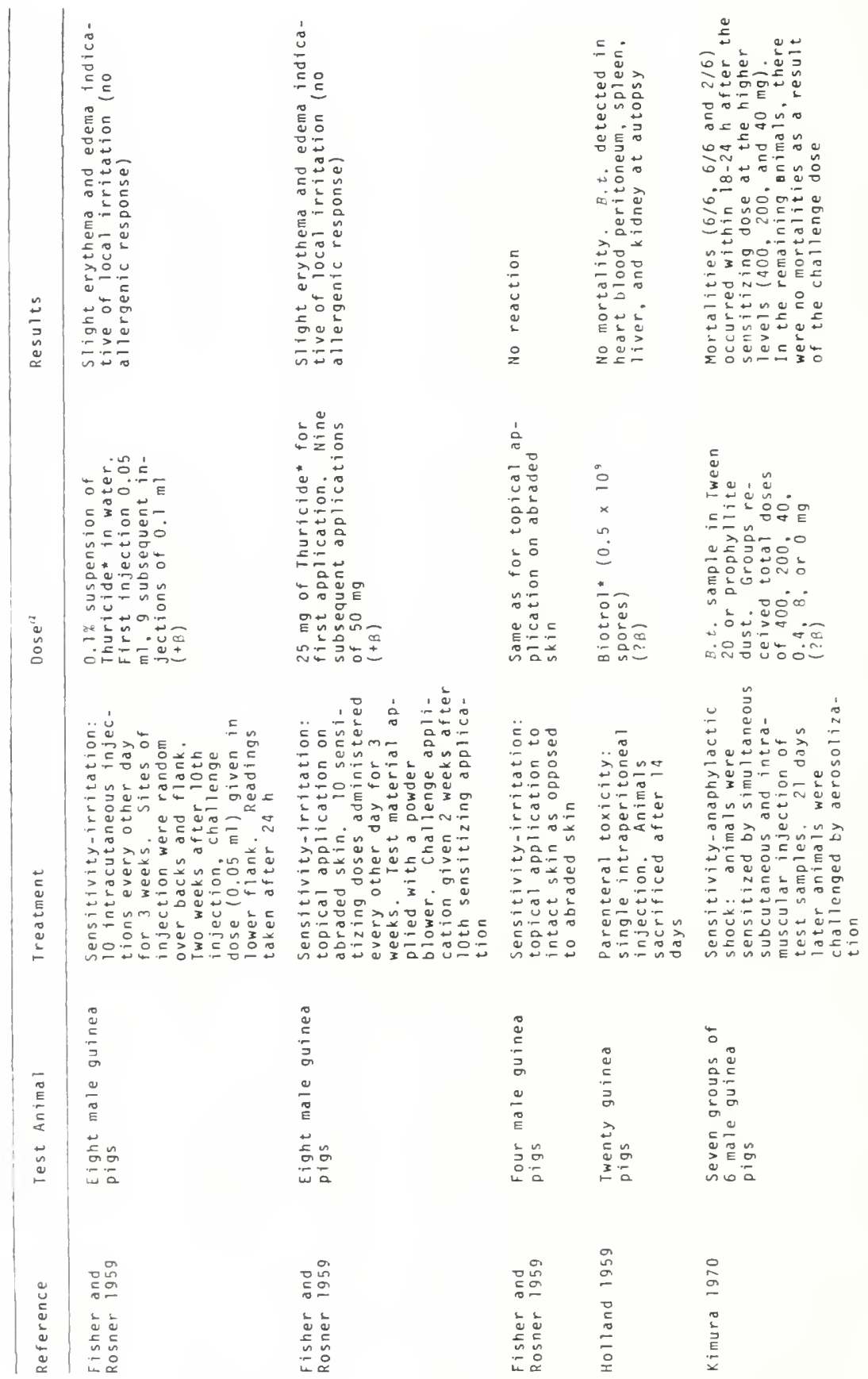




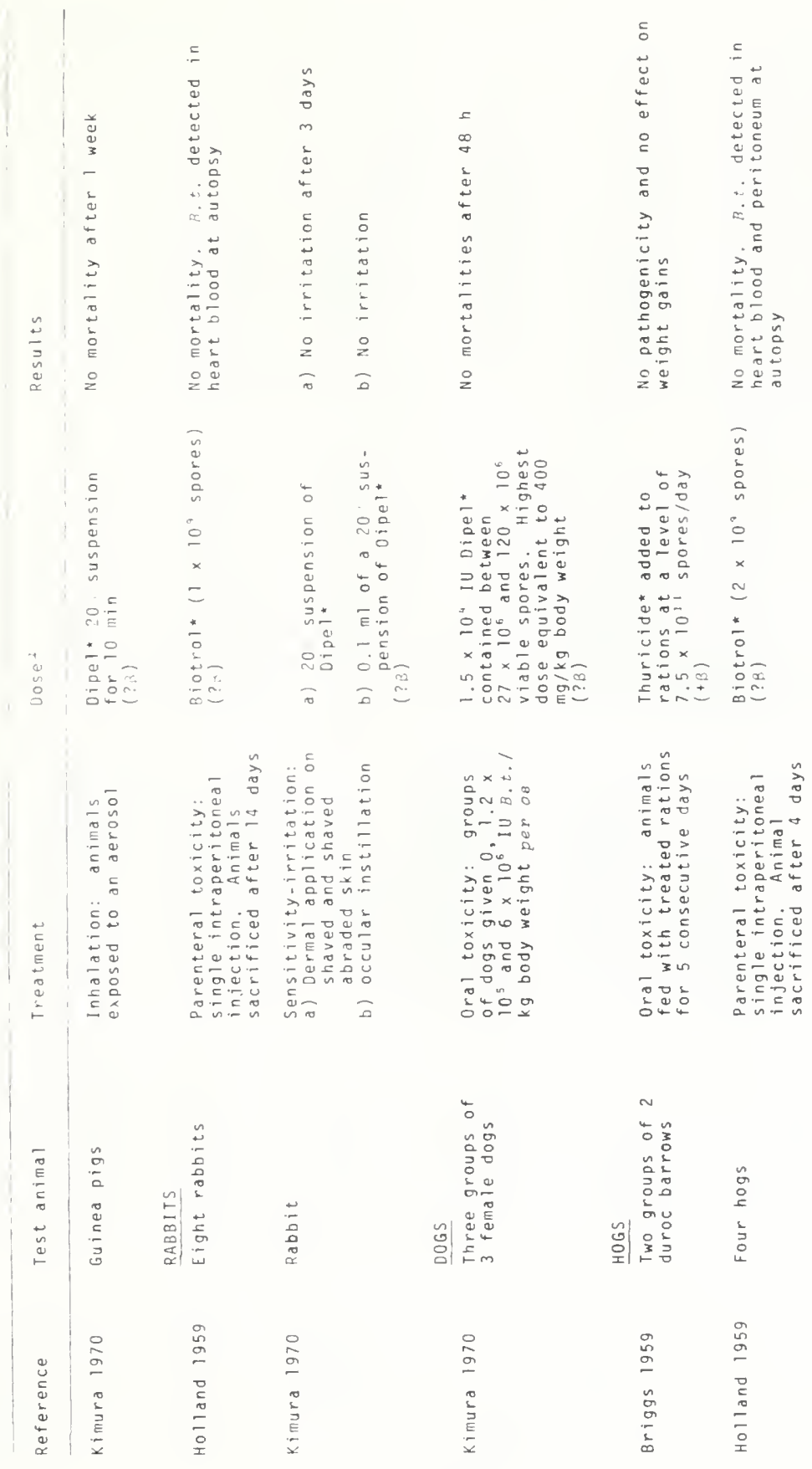




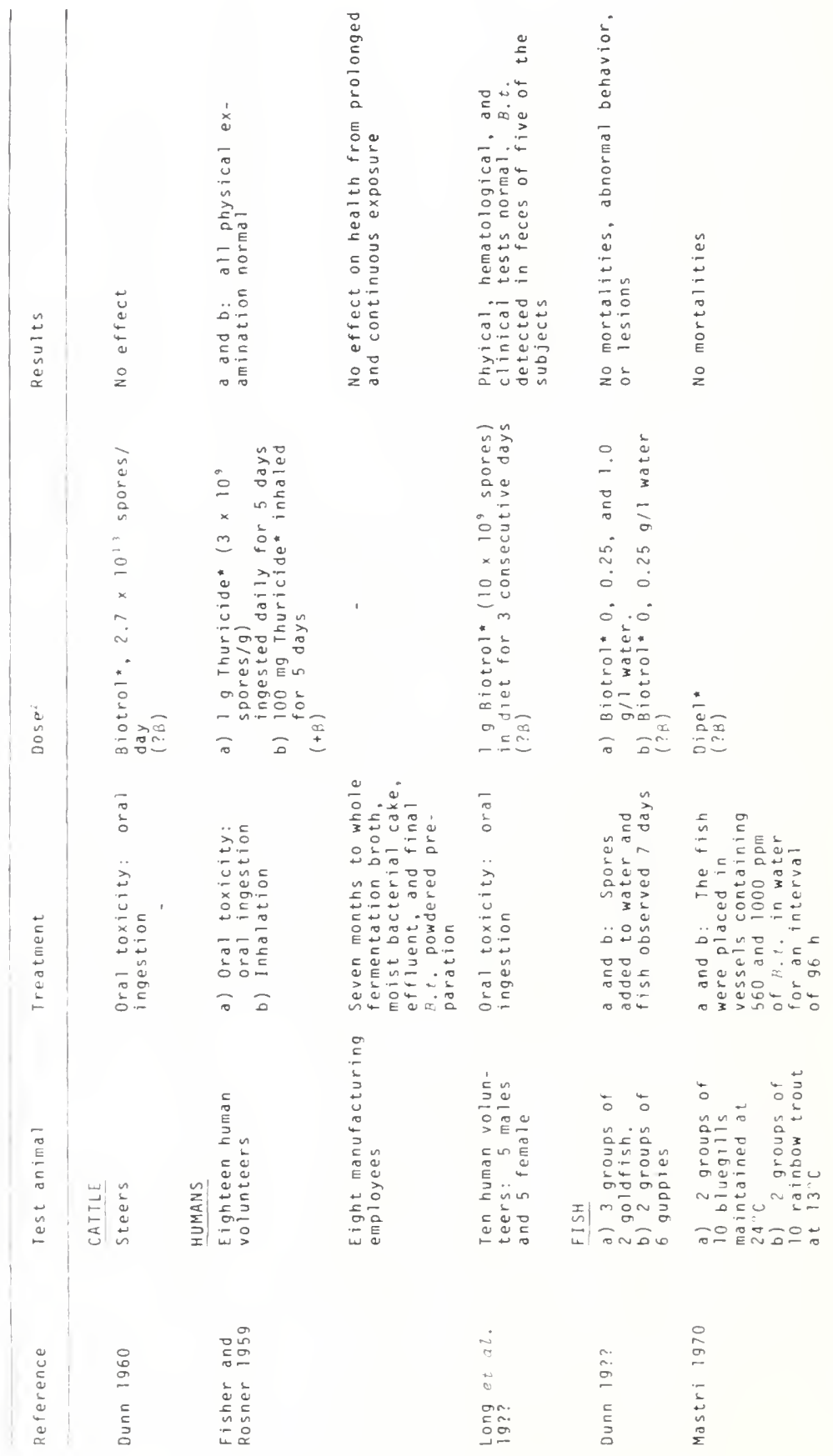




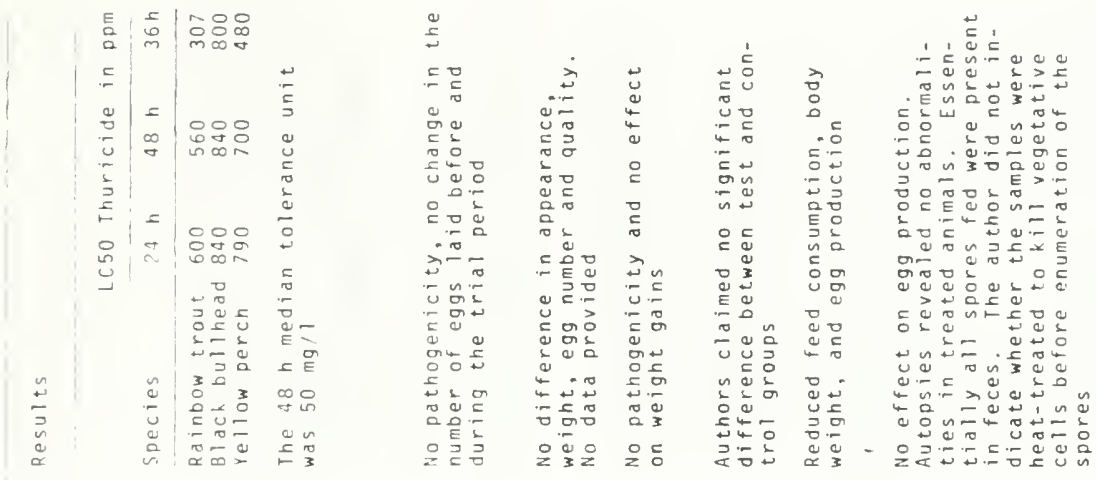
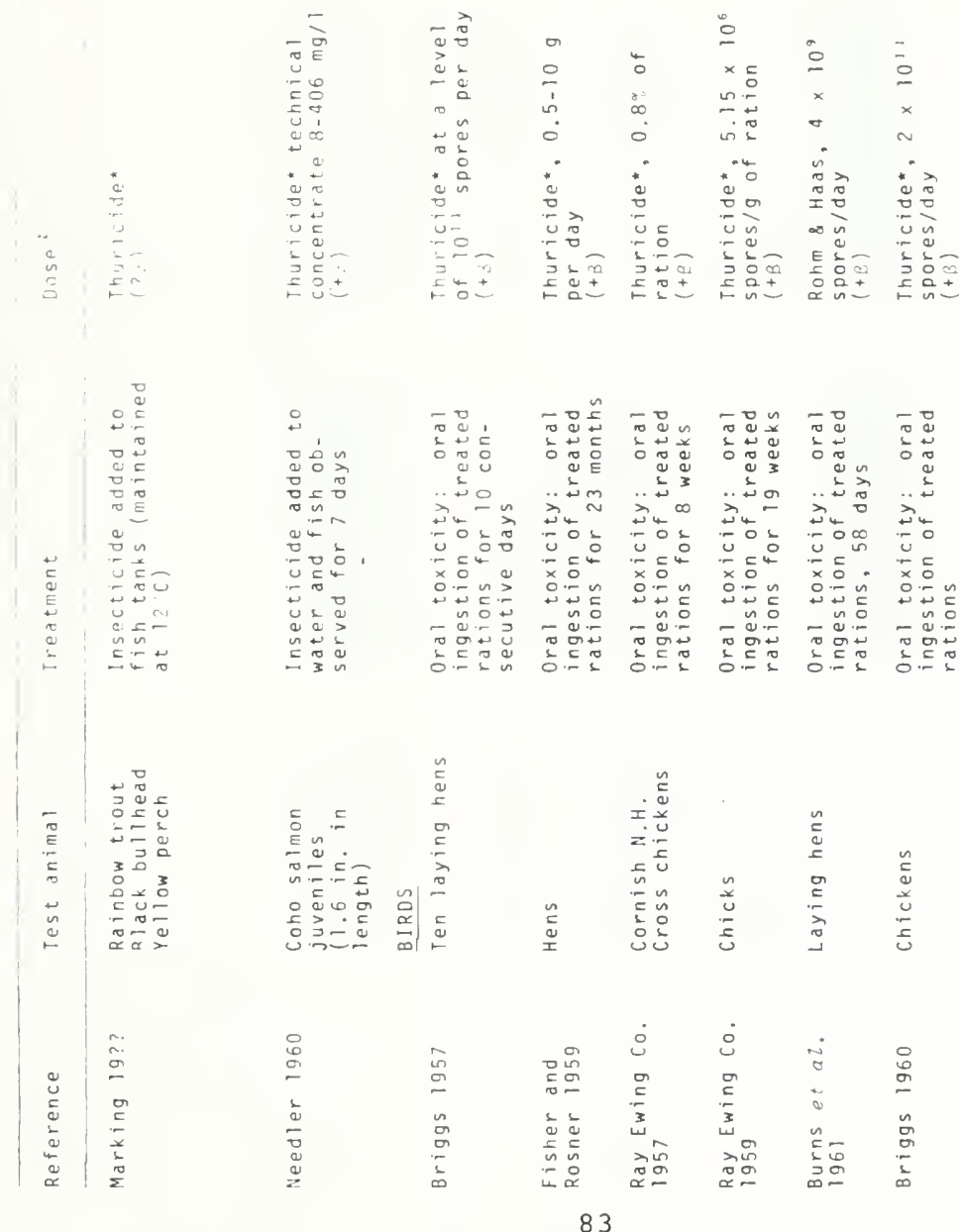

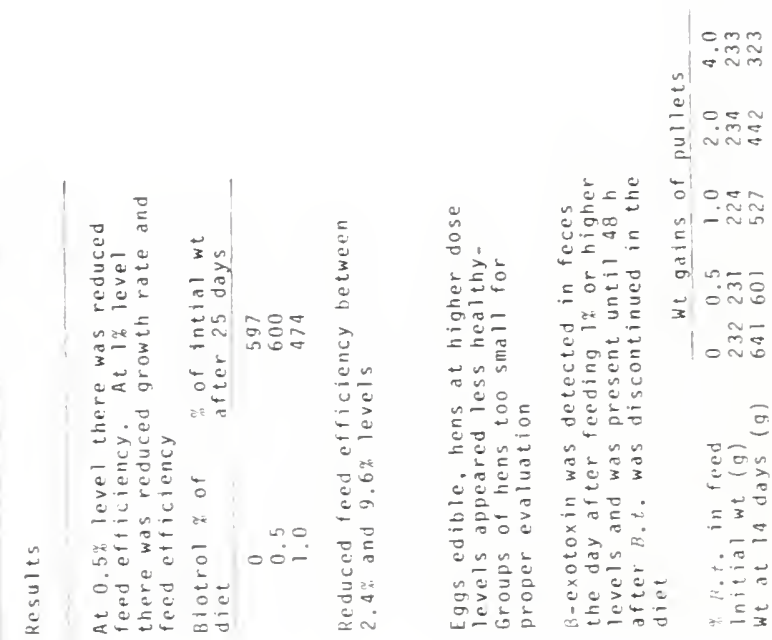

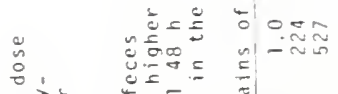

$=$ ì

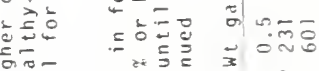

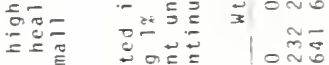

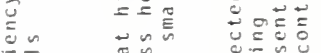

$\sim \tilde{E}: 0$

E⿱

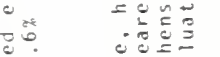

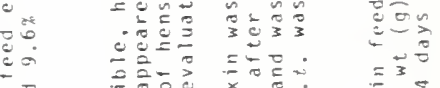

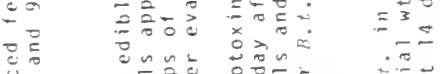

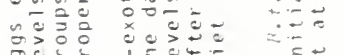

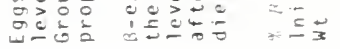

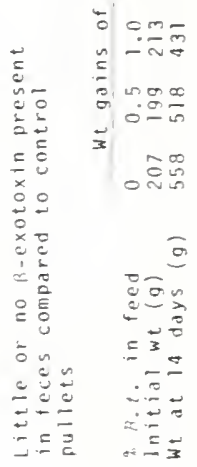

0
0
0
0
0
0
0
0
0
0
0

$\therefore=0$

$\therefore \circ$

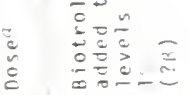
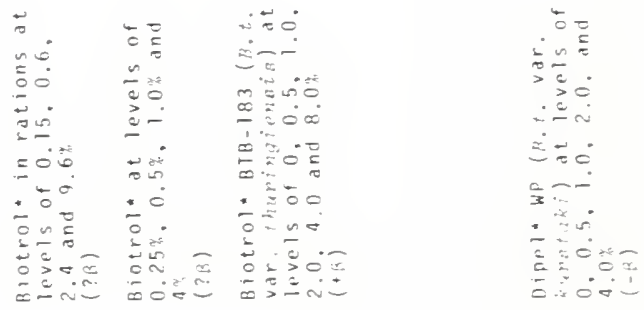

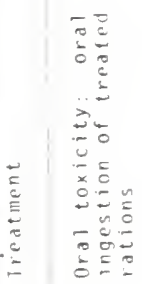

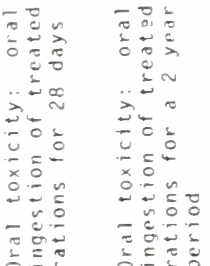

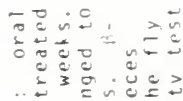

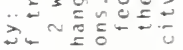

$\because \div \quad=0=2 \frac{0}{0}$

둔 $=\tau$

는

- C.- Eै ?

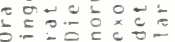

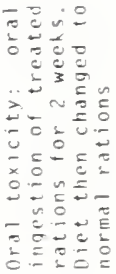

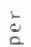

$\div$

造

宛

ए

Ẽ

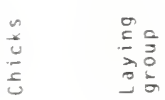

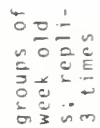

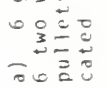

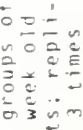

D记

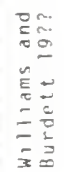

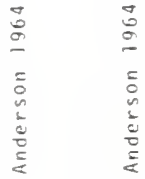

$\stackrel{m}{a}$
$\vdots$
$\vdots$
$\vdots$
0 


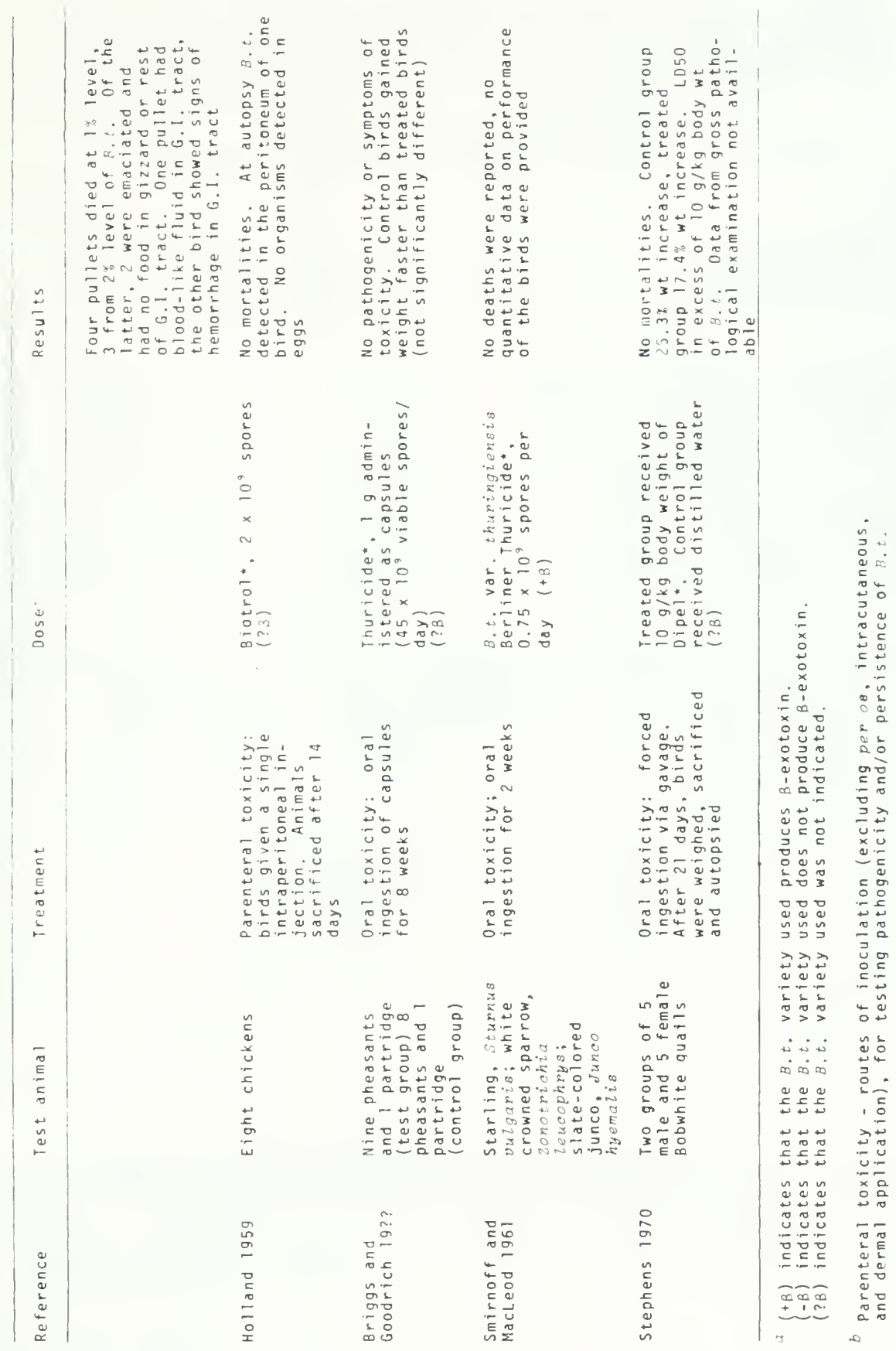


Appendix 4. (from Ghassemi et al. 1981).

SLMAEY OF IN VIVO TESTS CORUCTED TO EVALUATE SAFETY OF BACILLUS THLRINGIENSIS PREPARATIONS TO FISHES, BIRDS, AND MAMLALS

\begin{tabular}{|c|c|c|c|c|}
\hline \multirow[b]{2}{*}{ Species } & \multirow{2}{*}{$\begin{array}{c}\text { Numbers } \\
\text { of } \\
\text { Animals }\end{array}$} & \multicolumn{2}{|c|}{ Inoculum } & \multirow[b]{2}{*}{ Results } \\
\hline & & (billion/kg) & Route** & \\
\hline
\end{tabular}

Fishes

Ra inbow trout, black

bullnead, yellaw

perch, mosquito fish

Coho salmon juvenile

$\begin{array}{llll}40 & <0.01-4.5 & \text { TE } & \text { negative } \\ 23 & 300-1830 & \text { TE } & \text { toxicity at } \\ \text { higher doses }\end{array}$

Birds

Wilo pheasant

93000

diet negative

Partridge

25800

Cornish chick

Chick

$190 \quad 0.2$

diet negative

$48 \quad 300-1900$

diet negailve

New Hampshire iaying hen

$16 \cdot 1000-3000$

diet negative

Cockeral, Varitress

cross

$60 \quad 480-i 5,800$

die: negative

diet negative

Mammais

Mouse

48

$0.1-0.3$ cells

$0.04-2$ cells

if

se

$48 \quad 0.8-7.8$ spores

$48 \quad 20-160$ spores

$10 \quad 77$

$10 \quad 35$

so

po

ip

$10 \quad 20,000$

in

$10 \quad 2000$

Ra:

20

7700

$0.01-1.0$

Gurnee pig

$10 \quad 77$

$10 \quad 40$

$10 \quad 4000$

$10 \quad 0.3$

$10 \quad 16$

oo

diet nejat ve

ip negative

dies regutive

if negative
ip rejative

se localizec reaction.

a: injectior $5^{\circ}$ :e

Di silant erylneme or.

abradte si in

Swine, duroc

3185

Human

$\begin{array}{ll}18 & 0.2\end{array}$

dist

neçative

$5 \quad 0.02$

po negative

in nerative

* Vable spore count of wriale cultire preiaration trat in-ludto sibres, vego.

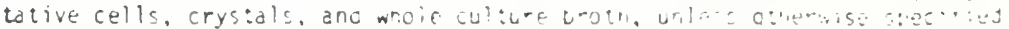

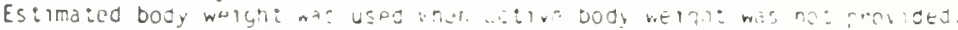

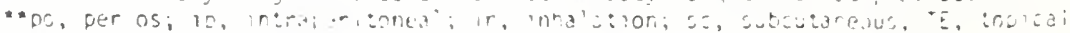

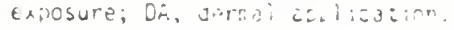


Appendix 4. (from Ghassemi et al. 1981).

SUMMARY OF IN VIVO TESTS CORDUCTED TO EVALUATE SAFETY OF BACILLUS THURINGIENSIS PREPARATIONS TO FISHES, BIRDS, AND MAMMALS

\begin{tabular}{|c|c|c|c|c|}
\hline \multirow[b]{2}{*}{ Species } & \multirow{2}{*}{$\begin{array}{l}\text { Numbers } \\
\text { of } \\
\text { Animals }\end{array}$} & \multicolumn{2}{|c|}{ Inocul um* } & \multirow[b]{2}{*}{ Results } \\
\hline & & $(0$ illion/kg) & Route** & \\
\hline \multicolumn{5}{|l|}{ Fishes } \\
\hline $\begin{array}{l}\text { Rainbow trout, black } \\
\text { bullhead, yellow } \\
\text { perch, mosquito fish }\end{array}$ & 40 & $<0.01-4.5$ & TE & negative \\
\hline Coho salmon juvenile & 20 & $300-1800$ & TF. & $\begin{array}{l}\text { toxicity at } \\
\text { higher doses }\end{array}$ \\
\hline \multicolumn{5}{|l|}{ Birds } \\
\hline Wild pheasant & 9 & 3000 & diet & negative \\
\hline Partridge & 2 & 5800 & diet & negative \\
\hline Cornish chick & 190 & 0.2 & diet & negative \\
\hline Chick & 48 & $300-1900$ & diet & negative \\
\hline $\begin{array}{l}\text { New Kampshire laying } \\
\text { hen }\end{array}$ & 16 & $1000-3000$ & diet & negative \\
\hline $\begin{array}{l}\text { Cockeral, Vantress } \\
\text { cross }\end{array}$ & 60 & $480-15,800$ & diet & neoative \\
\hline \multicolumn{5}{|l|}{ Mamma is } \\
\hline Mouse & $\begin{array}{l}48 \\
48 \\
48 \\
48 \\
10 \\
10\end{array}$ & $\begin{array}{l}0.1-0.3 \text { cells } \\
0.04-2 \text { cells } \\
0.8-7.8 \text { spores } \\
20-160 \text { spores } \\
77 \\
15\end{array}$ & $\begin{array}{l}\text { ip } \\
\text { sc } \\
\text { ip } \\
\text { sc } \\
\text { po } \\
\text { ip }\end{array}$ & $\begin{array}{l}\text { lethal dose, } 50: \\
\text { lethal dose, } 50: \\
\text { lethal dose, } 50: \\
\text { lethal dose, } 50: \\
\text { negative } \\
\text { abdominal irri- } \\
\text { tation; some } \\
\text { death } \\
\text { negative }\end{array}$ \\
\hline Rat & $\begin{array}{r}10 \\
100 \\
20\end{array}$ & $\begin{array}{l}2000 \\
7700 \\
0.01-1.0\end{array}$ & $\begin{array}{l}\text { po } \\
\text { diet } \\
\text { ip }\end{array}$ & $\begin{array}{l}\text { negative } \\
\text { negative } \\
\text { negative }\end{array}$ \\
\hline Guinea pig & $\begin{array}{l}10 \\
10 \\
10 \\
10\end{array}$ & $\begin{array}{l}77 \\
40 \\
4000 \\
0.3\end{array}$ & $\begin{array}{l}\text { diet } \\
\text { ip } \\
\text { ip } \\
\text { sc } \\
\text { OA }\end{array}$ & $\begin{array}{l}\text { regative } \\
\text { negative } \\
\text { negative } \\
\text { locailzec reaction } \\
\text { dt injection site } \\
\text { slight erytncma on } \\
\text { abraded skin }\end{array}$ \\
\hline Swine, duroc & 3 & 185 & diet & negative \\
\hline Human & 18 & 0.2 & po & negative \\
\hline & 5 & 0.02 & in & negative \\
\hline
\end{tabular}

- Viable spore count of whole culture preriaration that included siores, vege-

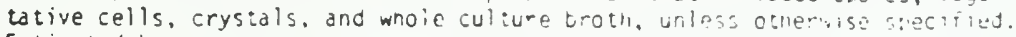

Estimated body wolght nat usad bnen setlve dody welght was no: provided.

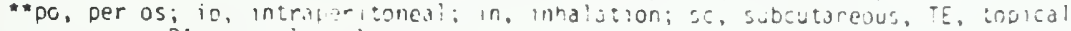

exposure; DA, Jermiai abilis aion. 
$+x$

$+$ 
